\title{
Coadaptation and malaria control
}

\author{
Carlos Eduardo Tosta \\ Laboratórios de Malária e de Imunologia Celular, Faculdade de Medicina, Universidade de Brasília, \\ Asa Norte, 70910-900 Brasília, DF, Brasil
}

\begin{abstract}
Malaria emerges from a disequilibrium of the system 'human-plasmodium-mosquito' (HPM). If the equilibrium is maintained, malaria does not ensue and the result is asymptomatic plasmodium infection. The relationships among the components of the system involve coadaptive linkages that lead to equilibrium. A vast body of evidence supports this assumption, including the strategies involved in the relationships between plasmodium and human and mosquito immune systems, and the emergence of resistance of plasmodia to antimalarial drugs and of mosquitoes to insecticides. Coadaptive strategies for malaria control are based on the following principles: (1) the system HPM is composed of three highly complex and dynamic components, whose interplay involves coadaptive linkages that tend to maintain the equilibrium of the system; (2) human and mosquito immune systems play a central role in the coadaptive interplay with plasmodium, and hence, in the maintenance of the system's equilibrium; the under-or overfunction of human immune system may result in malaria and influence its severity; (3) coadaptation depends on genetic and epigenetic phenomena occurring at the interfaces of the components of the system, and may involve exchange of infectrons (genes or gene fragments) between the partners; (4) plasmodia and mosquitoes have been submitted to selective pressures, leading to adaptation, for an extremely long while and are, therefore, endowed with the capacity to circumvent both natural (immunity) and artificial (drugs, insecticides, vaccines) measures aiming at destroying them; (5) since malaria represents disequilibrium of the system HPM, its control should aim at maintaining or restoring this equilibrium; (6) the disequilibrium of integrated systems involves the disequilibrium of their components, therefore the maintenance or restoration of the system's equilibrium depend on the adoption of integrated and coordinated measures acting on all components, that means, panadaptive strategies. Coadaptive strategies for malaria control should consider that: (1) host immune response has to be induced, since without it, no coadaptation is attained; (2) the immune response has to be sustained and efficient enough to avoid plasmodium overgrowth; (3) the immune response should not destroy all parasites; (4) the immune response has to be well controlled in order to not harm the host. These conditions are mostly influenced by antimalarial drugs, and should also be taken into account for the development of coadaptive malaria vaccines.
\end{abstract}

Key words: malaria - control - coadaptation - coevolution - infectron - vaccine - antimalarial drugs - mosquito insecticide - equilibrium

\section{MALARIA, A CHANGING CONCEPT}

The association of humans with plasmodia is probably as old as Humanity. However, our perceptions about the infection have been drastically changed throughout the time. In ancient times, and for a long while, malaria and several other infectious diseases were considered as due to God's punishment for human sins. During the Middle Age, the idea that the environment could affect human health by means of miasms associated with swamps was also applied to malaria. During the period of Renaissance, the Italian physician Girolamo Fracastoro introduced the concept of contagion, which was replaced by that of infectious agents three centuries later. Therefore, by the end of the XIX century malaria was considered as an infectious disease caused by plasmodia and transmitted by mosquitoes. The better understanding of the pathological aspects of the host-parasite

E-mail: cetosta@unb.br

Received 6 March 2007

Accepted 22 March 2007 relationships accomplished during the next century allowed to consider the major clinical-pathological manifestations of malaria as caused by an uncontrolled activation of the immune system by plasmodia, death sometimes occurring in the presence of minimal parasitemia or even in the absence of circulating parasites. Since the endothelium is the most affected structure in brain, kidney, and lung involvement, and the cells and molecules of the immune system are the major responsible for that, severe malaria could be considered as an immune endotheliopathy.

A novel view is emerging at the dawn of the XXI century: malaria as the result of disequilibrium of the system 'human-plasmodium-mosquito' (HMP). If this system is maintained in equilibrium, malaria does not ensue, and the result is asymptomatic plasmodium infection. A vast body of evidence supports this assumption and, as shown in this essay, all phenomena concerning the relationships among the components of the system HMP involve coadaptation. The recognition of these coadaptive linkages, leading to equilibrium of the system and evolution of its components, compels to a reinterpretation of the immunology, therapeutics and vaccinology of malaria, and may contribute to change the tenets of malaria control strategies. 


\section{ADAPTATION AND MALARIA}

It is postulated that the relationships between the three livings components associated with malaria - human, plasmodium, and mosquito - are always under the constraint of the phenomenon of adaptation. The different possibilities of adaptation are showed in Table I.

\section{TABLE I}

Possible phenomena of adaptation in the system humanplasmodium-mosquito

1. Adaptation of humans to plasmodia

- Immune response to plasmodia by humans

- Chronic and asymptomatic infections

- Selection of human genetic traits by plasmodia

2. Adaptation of humans to mosquitoes

- Immune response to mosquito salivary products

- Desensitization to mosquito salivary products

3. Adaptation of plasmodia to humans

- Strategies of plasmodium adaptation to the immune human

- Development of resistance to antimalarial drugs

4. Adaptation of mosquitoes to plasmodia

- Immune response to plasmodia by mosquitoes

- Development of refractoriness of mosquitoes to plasmodia

- Selection of mosquito genetic traits by plasmodia

5. Adaptation of plasmodia to mosquitoes

- Strategies of plasmodium adaptation to the immune mosquito

- Improvement of plasmodium development in the mosquito

- Selection of plasmodium genetic traits by mosquitoes

6. Adaptation of mosquitoes to humans

- Development of resistance to insecticides

- Man-induced behavioral changes of mosquitoes

\section{ADAPTATION OF HUMANS TO PLASMODIA}

The introduction of plasmodium into the human organism induces a series of reactions of the immune system aiming at the adaptation to the new situation. In the absence of therapeutic interventions, the following outcomes are antecipated: (a) absent or minimal clinical manifestations, with low and long-lasting parasitemia; (b) mild or moderate clinical manifestations, with variable parasitemia, which can be cleared by the immune system after several months; (c) severe or complicated malaria, frequently with high parasitemias, which can lead to death. These outcomes represent a wide range of situations and will depend, basically, on the degree of adaptability of the biological system human-plasmodium. Central in the determination of the levels of adaptation is the immune system. The life and the health of the human host will depend, to a great extent, on the adequate reaction of the immune system to the parasite. If well balanced, a state of equilibrium with the parasite will be reached, with minimal aggressions to the involved parts, and so it can be maintained for a long while. However, the under or over-functioning of the immune system is usually accompanied by disease of variable severity, and eventually by death. The deficient immune system is unable to control the growth of the parasite and infected people, usually children endowed with an immature immune system, suffer of high parasitemias, and sometimes die of severe anemia. If the immune system is overactive, due to the tremendous amount of antigenic material released in the circulation during schizogony, several pathological manifestations involving the endothelial lining of the vessels, particularly of the central nervous system, kidneys, and lungs, can cause the death of infected people.

\section{Immune response to plasmodia by humans}

Infection by plasmodia in areas of high transmission, as most of sub-Saharan Africa, starts very early in life. In the first 6 to 10 months of life children are usually protected from clinical malaria, mainly due to antiplasmodial antibodies transferred from the immune mother via placenta. During this period, they develop asymptomatic infection with low parasitemia (McGregor 1964). Therefore, adaptation of humans to malaria starts very early in life, although mostly due to factors inherited from the immune mother.

With the progressive decay of maternal antibodies, and before the full maturation of their own adaptive immune system, children present a period of high vulnerability to malaria that lasts a few years. The vast majority of cases of severe malaria, and the consequent over one million deaths that occur every year, happen at this period of life. In spite of this huge death toll, severe malaria constitutes a relatively rare event that occurs in about 1 to $2 \%$ of infected individuals (Greenwood \& Mutabingwa 2002). Why some children infected with Plasmodium falciparum develop a life-threatening disease, whereas the majority experience only a febrile illness is still not fully understood, but probably involves genetic factors related to the host and to the parasite.

Several strategies are used by the infected organism in an attempt to restrain the excessive growth of malaria parasite, and to adapt the organism to its presence. For this purpose, all components of the immune system are mobilized, including B lymphocytes that produce a broad array of antibodies, $\mathrm{CD}^{+}$and $\mathrm{CD}^{+} \mathrm{T}$ lymphocytes, $\mathrm{NK}$ cells, macrophages, and dendritic cells (see Table II).

The classical view of the host-parasite relationship sustains that the function of the immune system is to keep the organism free of infectious agents. However, if this was its real function the immune system should be considered a very inefficient system since it is not capable to destroy the thousands of different species of microorganisms that live and grow on and within the human organism, including the microbiota. A more realistic alternative view postulates that the function of the immune system is to keep the organism in equilibrium with the environment and, therefore, adaptation instead of destruction is the gold rule. The clinical manifestations of malaria, particularly the rare occurrence of severe and complicated forms of the disease, are indications of disequilibrium either due to an overgrowth of the parasite and/or to dysfunction of the immune system. 


\section{TABLE II}

Possible strategies used by the immune system to restrain the excessive growth and to adapt the organism to plasmodia

1. Phagocytosis by macrophages and dendritic cells

- Via immunoglobulin receptors

- Via complement receptors

- Via Toll-like receptors

2. B lymphocytes and antibodies

- Inhibition of the invasion of hepatocytes by sporozoites

- Increasing of phagocytosis of sporozoites (?)

-Antibody-dependent cytotoxicity of infected hepatocytes

- Inhibition of merozoite invasion of erythrocytes

- Interference with the intraerythrocytic development of plasmodium

- Increase of phagocytosis of merozoites and parasitized erythrocytes

- Complement-dependent lysis of parasites and parasitized erythrocytes

- Inhibition of cytoadherence of parasitized and nonparasitized erythrocytes

- Inhibition of endothelial sequestration of parasitized erythrocytes

- Neutralization of the pathogenic effects of cytokines (?)

- Inhibition of fertilization of gametes

- Inhibition of maturation of ookinetes

3. T lymphocytes and cytokines

- Cytotoxicity of parasitized hepatocytes by $\mathrm{CD}^{+}$and CD8 ${ }^{+}$lymphocytes

-Activation of macrophages and enhancement of phagocytosis

4. NK cells

- Cytotoxicity of parasites and parasitized erythrocytes (?)

Adapted from Tosta et al. (2005).

\section{Chronic and asymptomatic infections}

It is important to take into account that as many as 98 to $99 \%$ of the 350 to 500 million cases of malaria that occur yearly (WHO 2005a) present a mild or moderate clinical course, and recovery ensues by antimalarial treatment or spontaneously, after several months of infection (Miller et al. 1994). This chronic feature of untreated malaria represents a high degree of adaptability between host and parasite. During this period, infected individuals are generally asymptomatic or present very mild clinical manifestations, and usually have low parasitemias, sometimes detected exclusively with very sensitive molecular methods. Asymptomatic infections have been described either at the African areas of high endemicity (Greenwood 1987, Trape et al. 1994, OwusuAgyel et al. 2001), or at the American areas of lower transmission (Andrade et al. 1995, Alves et al. 2002, Marcano et al. 2004). In both epidemiological contexts, asymptomatic infections exceedingly outnumber the symptomatic cases. These observations lead to the conclusion that the state of equilibrium (adaptation) is the rule in human host-plasmodium relationships, and that clinical manifestations of malaria can be considered as a stage before equilibrium was reached or was lost. Indeed, a longitudinal assessment carried out with a popu- lation living at an Amazonian endemic area found that 104 individuals infected with plasmodium out of 144 (72.4\%) were initially asymptomatic, 45 (31.3\%) continued to be asymptomatic for the next 30 days, and 36 (25\%) continued to be so for 150 days of follow-up (Ladeia-Andrade 2005, Coura et al. 2006).

In regions where the prevalence of malaria is high, many individuals harbor multiple $P$. falciparum genotypes that survive at low parasitemia during the duration of asymptomatic infection (Anderson et al. 2000). Clinical episodes of malaria are caused by a new infection, the majority of which are of a single genotype (Jeffares et al. 2007).

\section{Selection of human genetic traits by plasmodia}

Malaria has been considered the strongest known force for evolutionary selection in the recent history of the human genome (Kwiatkowski 2005). Indeed, over the last 10,000 years, malaria has resulted in the selection of hundreds, if not thousands, of genetic variants that confer some degree of protection against death from the disease (Williams 2006). Therefore, plasmodia are considered to be playing a profound impact on recent human evolution.

The notion that selection during longer periods of exposure to malaria may have a major effect in modifying the constitution of human genome was first recorded by Beet (1946) who showed lower rates of malarial infection among carriers of the sickle cell trait than among nonsicklers. Two years later, Haldane noticed that the extremely high frequency of thalassemia in certain racial groups from the Mediterranean region might reflect an unusually high mutation rate as a result of the prolonged exposition to malaria (Haldane 1948). The association between malaria and thalassemia was further confirmed in other regions of the world. For instance, it was showed in inhabitants of the malaria endemic areas of Papua New Guinea and in parts of Melanesia a frequency of the $\alpha$ thalassemia gene proportional to the prevalence of malaria (Flint et al. 1986). The observation that hemoglobin variants are unevenly distributed among tropical populations, and the discovery that in every population in which thalassemia is common different patterns of mutation are described suggest that these conditions must have arisen independently in different parts of the world and reached their high frequency by locally-acting factors such as selection and drift (Flint et al. 1993).

It is now recognized that malaria represents the evolutionary driving force behind the selection of several genetic traits in humans, including the structural variants of $H B B$ gene, which encodes the $\beta$-globin chain, and leads to the occurrence of atypical hemoglobins like $\mathrm{HbS}, \mathrm{HbC}$, and $\mathrm{HbE}$ (Agarwal et al. 2000, Modiano et al. 2001, Oharshi et al. 2004). Hemoglobin S, the cause of sickle-cell disease, has arisen independently in different locations and is maintained at $\sim 10 \%$ frequency in many malaria-endemic regions (Flint et al. 1998). In its heterozygote presentation, $\mathrm{HbS}$ causes a 10 -fold reduction of the risk of severe malaria (Ackerman et al. 2005).

Other malaria-induced selection of genetic traits in humans include: (1) regulatory defects of $H B A$ and $H B B$ genes, which cause $\alpha$ and $\beta$ thalassemias; (2) variation in 
the structural protein SLC4A1, which causes ovalocytosis; (3) mutations in other red cell membrane associated proteins such as ankyrin, spectrin or protein 4.1, which cause hereditary elliptocytosis or spherocytosis; (4) variation in the chemokine receptor $F Y$, which causes the Duffy-negative blood group; (5) deletion in the glycophorin C (GYPC) protein, the receptor for P. fal-ciparum protein EBA-140; (6) polymorphisms of the red cell enzyme gene $G 6 P D$, which causes glucose-6-phosphate dehydrogenase deficiency; (7) polymorphisms of HLADR genes; (8) polymorphisms of the tumor necrosis factor promoter region; (9) polymorphisms of ICAM and CD36 proteins; (10) mutations in the PKLR gene, which causes pyruvate kinase deficiency; (11) defects in complement receptor-1 (CR-1) (Weatherall et al. 1997, Carter \& Mendis 2002, Sabeti et al. 2002, Weatherall \& Clegg 2002, Kwiatkowski 2005, Min-Oo \& Gros 2005, Williams 2006).

A very interesting point was raised by Carter and Mendis (2002): how long does it take malaria to select for human polymorphisms? These polymorphisms are found in elevated frequencies usually only in populations which have been exposed to malaria for at least several hundred years. Mutations which are moderately protective against malaria, such as the thalassemias and glucose-6-phosphate dehydrogenase deficiency, are generally the first to reach elevated frequency under selection by malaria. These are the malaria-selected polymorphisms which predominate around the shores of the Mediterranean Sea, where malaria arrived between 2500 and 2000 years ago. In regions in which more than 2000 to 3000 years of selection by malaria has taken place, namely, in Africa, parts of the Middle East, southern Asia, and Melanesia, mutations are found which are highly protective against malaria in heterozygous combination, but which also carry a high balancing cost in homozygous combination. These are the genes for sickle cell hemoglobin and ovalocytosis. Longest of all, many thousands or tens of thousands of years, may be the selection for alleles whose protective effects against malaria are expressed only, or mainly, when they are present in homozygous combination. Such is the allele for hemoglobin C, which, in homozygous combination, protects strongly against $P$. falciparum malaria and which has probably not yet reached equilibrium frequencies even after several thousand years of selection in West Africa. Such, also, is the allele for RBC Duffy negativity, which, only in homozygous combination, protects solely and absolutely against $P$. vivax malaria (Carter \& Mendis 2002).

The shaping of human genome by malaria parasites, which has been in progress for the last 10,000 years, is helping to select people more resistant to the infection by plasmodium or to the severe forms of malaria, by means of the death of those more susceptible individuals. However, the extra price paid by this selection is that the genetic burden, in the form of thalassemias, sickle cell disease, glucose-6-phosphate dehydrogenase deficiencies, and ovalocytoses, is of the same order as the residual burden of malaria itself. About one-third of a million to half a million babies are born each year with severe forms of these inherited disorders (Weatherall \& Clegg 2001).

\section{ADAPTATION OF HUMANS TO MOSQUITOES}

Humans are living in close association with mosquitoes probably since their emergence. This association involves exchange of material between them: the mosquitoes suck human blood, and humans receive mosquito's saliva. In individual terms, the tiny amount represented by the salivary material of one mosquito may be considered inexpressive. However, in some areas of Sub-Saharan Africa during the course of a single night, several hundred mosquitoes of the Anopheles gambiae complex are collected in a room, $1-5 \%$ of which are infectious, and people may receive over 1000 infected bites per year (Greenwood \& Mutabingwa 2002), which represent a total of something between 19,800 and 99,000 anopheline bites per year. These figures do not include the bites of the far more frequent culicine mosquitoes. The impact of this constant and prolonged contact with mosquitoes on human adaptation to these arthropods is difficult to be drawn, but probably includes the development of immune response to mosquito salivary products, and the process of natural desensitization to the allergic reaction caused by this material.

\section{Immune response to mosquito salivary products}

At least 14 orders or families of arthropods, containing over 400 different genera and more than 15,000 species, independently evolved to feed on vertebrate blood (Ribeiro 1995). To accomplish this task, these animals evolved complex salivary components capable to affect blood clotting, platelet aggregation, vascular contraction, host immunity, inflammation, and angiogenesis (Calvo et al. 2006a). Female, but not male mosquito salivary glands, possess several antihemostatic components to facilitate acquisition of blood, while both sexes have activities related to digestion of the sugar meal, as well as antimicrobial peptides. Studies on adult female A. gambiae transcriptomes indicated a set of $\sim 70$ proteins and peptides possibly secreted in saliva that presumably facilitate sugar and blood meals (Calvo et al. 2006b). The introduction into the dermis of the host of such an enormous variety of antigenic components will induce, at the point of the bite or systemically after reaching the draining lymph node, a complex array of responses of the immune system.

The first components of the immune system to react to the presence of saliva proteins and peptides are dermal macrophages and dendritic cells, which will capture and process these products and transform them in antigens that will activate $\mathrm{T}$ lymphocytes, both locally or, mainly, in the draining lymph nodes to where antigen loaded dendritic cells migrate. B lymphocytes are also activated by cross-signaling with $\mathrm{T}$ lymphocytes and antibodies of different specificities are produced, particularly IgE and IgG (Peng et al. 2004a). The local immune response is amplified by the attraction of inflammatory cells due to the chemotactic effect of some components of mosquito saliva (Owhashi et al. 2001). An important manifestation of the immune response to saliva components is degranulation of dermal mast cells and release of histamine and leukotriene C4 (Horsmanheimo et al. 1996). Although the binding of saliva antigens to specific 
IgE molecules attached to mast cells receptors is supposedly the major cause of degranulation of these cells, some other mechanisms are probably operative, since release of histamine also occurs in individuals not previously sensitized to saliva components (Demeure et al. 2005).

Apart from causing an immune-mediated local reaction, mosquito saliva components have powerful immunomodulatory effects, capable either to depress host immune response or exacerbate it in such way that, in very rare cases, severe lymphoproliferative syndrome and oncogenesis can occur in association with the inhibition of $\mathrm{T}$ and $\mathrm{B}$ lymphocytes and of the inflammatory response (Wasserman et al. 2004, Titus et al. 2006). Severe hypersensitivity to mosquito bites is characterized by intense local skin reactions and systemic symptoms such as high fever, lymphadenopathy, and hepatosplenomegaly. These patients often have natural killer cell lymphocytosis associated with chronic Epstein-Barr virus infection (Asada et al. 2005, Asada 2007).

What is the adaptive meaning of host immune response to mosquito bites? The continuous contact with salivary antigenic components lead to the development of immunoregulatory mechanisms and, therefore, to a progressively better balanced immune response. The consequence of this adaptive process is the decrease of the skin hypersensitivity reactions to mosquito saliva.

\section{Desensitization to mosquito salivary products}

The introduction in the skin of saliva by mosquito bites usually causes local transient pruritic papules. In some individuals, however, mosquito bites cause atypical severe large vesicular, necrotic, or ecchymotic local allergic reactions at the bite sites or, less commonly, acute systemic allergic reactions, including urticaria, angioedema of the skin or mucous membranes (including the larynx), wheezing, dyspnea, hypotension, and decrease or loss of consciousness (McComack et al 1995, Peng et al. 2004a). The magnitude of the reactions varies with the mosquito species (Demeure et al. 2005), but depends mostly on the degree of sensitivity of the bitten person. They are mild in unsensitized persons and may become more pronounced if allergic sensitization to saliva occurs. The reaction to saliva components is caused by IgE-dependent mast-cell degranulation and also delayed-type hypersensitivity, due to the local accumulation of T-lymphocytes and macrophages.

Risk factors for more severe local reactions include immunodeficiency, young children and visitors to an area with new exposure to indigenous mosquitoes (Shibasaka et al. 1986, Simon \& Peng 1999, Engler 2001). What does it tell us? First, that the severity of the sensitivity reaction to mosquito saliva depends on the absence of efficient immunoregulatory mechanisms, as occurs in young children and in immunodeficiency. Secondly, that the frequent exposition to mosquito bite induces a state of progressive desensitization (Peng et al. 2004b). This is probably the reason why people living in areas where they a submitted to frequent mosquito bites appear to be less affected by them than newcomers. They supposedly are equally bitten but do not take notice of that because they do not perceive the bites. This is an important mechanism of adaptation of people to this itchy nuisance.

The mechanism underlying desensitization to mosquito bites is immune tolerance, a powerful adaptive function of the immune system. As a consequence of the continuous contact with salivary antigens, regulatory loops formed by cells ( $\mathrm{T}$ lymphocytes, macrophages, and dendritic cells) and molecules (antibodies, cytokines, hormones, and neuropeptides) are developed and modulation of the immune response ensues. These immunomodulatory mechanisms lead to an enhancement of the efficiency of the immune response (blockage of the toxic effects of salivary components) and decrease its noxious effects.

\section{ADAPTATION OF PLASMODIA TO HUMANS}

The very long-lasting association between malaria parasite and the human host imposed the development of several strategies of survival by both partners, which operated through selective processes. The consequence is adaptation. More recently, malaria parasites had to face a new challenge: to warrant their survival in the presence of antimalarial drugs. Again, as a consequence of selection, the appearance of drug-resistant variants of malaria parasite can be considered as part of the general phenomenon of adaptation. The same applies to the selection of genetic traits of the malaria parasite by the human host.

\section{Strategies of plasmodium adaptation to the immune human}

Plasmodium found in the erythrocyte an ideal ecological niche: a metabolically adequate environment, surrounded by a membrane devoid of major histocompatibility complex molecules. This means that intraerythrocytic plasmodium is relatively protected from the hostile surroundings of the immune host by the erythrocyte membrane, and is not detected by $\mathrm{T}$ lymphocytes. However, even during the intra-erythrocytic stage, malaria parasites are not free from recognition by the immune system: several antigens synthesized by the parasite are exported to the erythrocyte membrane and play different functions. For instance, the $P$. falciparum erythrocyte membrane protein 1 (PfEMP1) is central in the process of adherence of parasitized erythrocytes to the endothelium of post-capillary venules and thus prevents the capture of parasites by spleen cells during circulation. The crucial importance of PfEMP1 for $P$. falciparum survival made this protein one of the more polymorphic molecules of the parasite. Since PfEMP1 is an immunogenic protein, antibodies induced by this molecule can inhibit the binding of P. falciparum-infected erythrocytes to it and, therefore, impede the continuation of the vital cycle of the parasite. To circumvent the consequences of this immune response, the parasite developed the ability to vary PfEMP1 by switching its expression between members of the var multigene family (Kyes et al. 2001, Flick \& Chen 2004). The genome sequencing of the strain 3D7 of $P$. falciparum showed three multigene families involved in antigen variation: the var gene family with 59 intact copies, the rif (repetitive interspersed family) gene family with 149 , 
and the stevor (subtelomeric variant open reading frame) gene family, with 28 genes interspersed near the var genes (Gardner et al. 2002).

The way different var gene expression is switched by the parasite is not completely clear. Recent findings indicate that epigenetic programs associated to heterochromatin silencing and histone acetylation are operative (Duraisingh et al. 2005, Freitas-Júnior et al. 2005). As P. falciparum switches through its antigenic repertoire, it appears likely that only a small portion of the population will actually survive. As human immunity to the current var product expressed in the infection builds up and starts to eliminate the parasites, a small proportion that have switched to another var gene in the repertoire escapes immunity, expands and dominates the infection (Hastings et al. 2004).

The importance of antigenic variation for the life and evolution of malaria parasite is evidenced by the amount of its genome involved in this phenomenon. It is estimated that $3.9 \%$ of the 5268 predicted protein-encoding genes, comprising a total of 205 genes, have a postulated role in evasion of the host immune response (Kooij et al 2006).

The different strategies malaria parasites use for overcome the harshness of their life in the immune host are presented in Table III.

TABLE III

Strategies of plasmodium adaptation to the immune host

Antigenic diversity $\rightarrow$ escape from the immune response

-Antigenic polymorphism

- Antigenic variation

Molecular mimicry $\rightarrow$ common molecules between host and parasite

- Difficulty of recognition by the immune system

Induction of pro-plasmodium antibodies $\rightarrow$ increase parasite survival

- Competition with anti-parasite antibodies

- Increasing of sporogony

Depression of the host immune system $\rightarrow$ reduction of reactivity to parasite

-Alteration of phagocytic and plasmodicidal capacities, and antigen processing and presentation of macrophages and dendritic cells

- Depression of $\mathrm{CD}^{+}$and $\mathrm{CD}^{+} \mathrm{T}$ lymphocytes activation

by $\mathrm{CD}^{+} \mathrm{T}$ lymphocytes

- Induction of cytokines that depress the immune response

(IL-10 and TGF- $\beta$ )

- Inhibition of $\mathrm{CD}^{+} \mathrm{T}$ lymphocytes by dendritic cells

Adapted from Tosta et al. (2005).

\section{Development of resistance to antimalarial drugs}

Resistance of plasmodium to antimalarial therapy has been described in endemic areas throughout the world as a consequence of drug pressure. When the drug is used either in inadequate amounts, high frequency or is slowly metabolized resistant mutants are more readily selected by positive natural selection. Mutations arise spontaneously and affect the structure or function of the drug target in the malaria parasite, or inhibit the access of the drug to that target (WHO 2005b). Mutant parasites are selected if antimalarial drug concentrations are sufficient to inhibit multiplication of susceptible parasites but are inadequate to inhibit the mutants - a phenomenon known as drug selection (Das \& Dash 2007).

Resistance to antimalarial drugs is due to polymorphisms in a variety of genes including the Plasmodium falciparum chloroquine resistance transporter (Pfcrt) for chloroquine resistance (Bray et al. 2005), the gene of dihydro-folate reductase for pyrimethamine (Gregson \& Plowe 2005), of dihydropteroate synthase for sulfa drugs (Gregson \& Plowe 2005), and of cytochrome b for atovaquone (Srivastava et al. 1999). However, these polymorphisms are not sufficient to completely describe drug resistance in $P$. falciparum, because often their effects vary with strain genotype and drug concentration (Sidhu et al. 2002). Therefore, although polymorphisms can influence drug resistance, different strains of $P$. falciparum may also rely on alternative mechanisms of gene regulation to overcome the selective pressures of antimalarial drugs. These mechanisms may include overexpression of transporters in response to drug exposure, induction of alternative pathways to bypass the effect of the compounds or repression of genes that exacer-bate the deleterious effects of the drug (Llinás et al. 2006).

Mutation of the $P$. falciparum multi-drug resistance 1 (pfmdrl) gene, located on chromosome 5 and encoding the P-glycoprotein 1, was initially considered as the mechanism responsible for the development of the chloroquine-resistant phenotype. However, a direct association of mutations in this gene with resistance could not be proved (Wellems 1990). It has recently been demonstrated that copy number amplification of the pfmdrl gene is associated to resistance of $P$. falciparum to chloroquine, and also to some structurally unrelated antimalarial drugs as mefloquine, halofantrine and artemisinin derivatives (Nair et al. 2007). It is, therefore, not surprising the finding of Sidhu et al. (2006) of increased susceptibility of isolates of $P$. falciparum to mefloquine, lumefantrine, halofantrine, quinine, and artemisinin when the copy number of pfmdrl was decreased by gene disruption. The demonstration that increased number of pfmdrl copies is associated with multi-drug resistance is particularly worrying since it confers heightened resistance to both components of combination therapies (mefloquine-artesunate and lumefantrine-artemether) that are being introduced globally in an attempt to reduce the rate of evolution of drug resistance in malaria parasites (Price et al. 2006).

Another gene, the $P$. falciparum chloroquine resistance transporter ( $p f c r t$ ) gene, has been demonstrated to be responsible for conferring resistance to chloroquine. An amino acid mutation, K76T, was shown to present a strong positive correlation with the chloroquine resistant varieties of malaria parasites (Sidhu et al. 2002). Several studies have reported highly reduced genetic diversity surrounding K76T in the pfcrt gene, which indicates that the mutation has been a target of positive Darwinian natural selection, although this possibility does not appear to occur everywhere (Das \& Dash 2007). 
Although the mechanisms involved in the acquisition of drug resistance by malaria parasites are not clear, there is no doubt that the speed it occurs is far faster than that new antimalarial drugs are developed. This is a demonstration that the astonishing ability of plasmodia to overcome new challenges, that means, to adapt to novel situations.

\section{Selection of plasmodium genetic traits by humans}

The prolonged pressure exerted by the overwhelming host immune system shapes the genome of plasmodia leading to the selection of the fittest ones. The differences in the genomes of different isolates of $P$. falciparum (Kidgell et al. 2006) are consistent with the idea that the human immune system and antimalarial drugs are driving parasite evolution. The higher rate of accumulation of DNA insertions in laboratory isolates, when compared to that of clinical isolates (Jeffares et al. 2007) points to a second role of the host in the selection of malaria parasite: the elimination of those presenting nonproductive alterations of their genomes and, therefore, tightens their variability.

The selection of genetic traits of plasmodia by the human host is apparent in two situations: the differences of virulence and of drug resistance among isolates. The reasons of the variation of virulence among different isolates of malaria parasites are not as yet clear (Hasting et al. 2004), but certainly depends on selective processes that take place in the host. It has been proposed that virulence occurs as a consequence of the large parasite density required to effectively eliminate mutations or nullify them through compensatory mutations, the evolutionary optimal level of virulence being determined by the conflicting necessity of removing mutations balanced against the need to minimize host mortality (Hasting et al. 2004). As showed by Anderson et al. (2000), in areas of malaria transmission many individuals harbor multiple parasite genotypes that survive at low parasitemia during asymptomatic infection. This observation indicates that the interplay with the host leads to the modulation of parasite virulence and they can reach a state of equilibrium.

\section{ADAPTATION OF MOSQUITOES TO PLASMODIA}

\section{Immune response to plasmodia by mosquitoes}

Male and female gametocytes, taken up with the blood meal, undergo gametogenesis within the lumen of the mosquito midgut. Fertilization takes place and the resulting zygote undergoes meiosis and develops into the motile ookinete. Approximately one day after the infectious blood meal, the ookinete crosses the peritrophic matrix lining the midgut lumen and subsequently the midgut epithelium itself. Although the great majority of parasites are lost during midgut invasion, the most crucial step in the sexual development of a parasite, the presence of just a few surviving ookinetes is sufficient to establish successful transmission. Soon after invasion they transform into oocysts that undergo serial mitotic divisions, with each one producing several thousand sporozoites (Vlachou \& Kafatos 2005, Matuschewski 2006a).
About two weeks after the blood meal sporozoites are released into the hemocel, the open circulatory system of the mosquito. From here they reach the salivary glands and again traverse an epithelium, in this case to penetrate into the salivary gland lumen, where they mix with the saliva and are injected into the next vertebrate host. The fact that the parasite must cross two mosquito epithelial barriers and circulate within the hemolymph creates obvious opportunities for the epithelial and humoral immune responses of the mosquito to react to the parasite (Michel \& Kafatos 2005).

The mosquito immune response is triggered by the invasion of the midgut epithelium by ookinetes, and also some ill-defined factors of the host blood (Dong et al. 2006), leading to the activation of different mechanisms such as the coagulation of hemolymph, the melanization of the invading parasite by activation of the prophenoloxidase cascade, and the action of antimicrobial peptides as defensins, cecropins, gambicin and attacins (Michel \& Kafatos 2005). It has been shown that the number of oocysts is significantly reduced in mosquitoes transfected with the cecropin 1 gene (Kim et al. 2004).

Melanin synthesis plays important roles in the development and physiology of all insects; it is required for the hardening of the exoskeleton and pigmentation during the life cycle, and for wound healing after injury (Michel \& Kafatos 2005). In addition, pathogens can be immobilized by formation of a surrounding melanotic capsule and are killed apparently by the local production of free radicals (Kumar et al. 2003). However, the increased melanizing activity of $A$. gambiae does not appear to affect the development of $P$. falciparum (Michel et al. 2006). Furthermore, a pedigree analysis of mosquito populations in Mali excluded parasite melanization as a major resistance mechanism, indicating that the parasite is quite safe once ookinete transformation is successfully completed (Riehle et al. 2006).

Besides the mainly humoral defense mechanisms, mosquitoes display a variety of cellular immune responses mediated by their blood cells, the hemocytes. Mosquito hemocytes have the ability to phagocytize bacteria and malaria parasites (Hillyer et al. 2003).

Different adaptive strategies are used by the mosquito to cope with the presence of malaria parasites and their complexity are the result of the long-lasting association between the species. It is possible to postulate, as happens with other host-parasite systems, a wide range of outcomes of the mosquito-plasmodium interplay: from the complete destruction of the parasite to the death of the mosquito. However, the high prevalence of malaria in the world indicates that adaptation is the most frequent event in the association mosquito-plasmodium.

\section{Development of refractoriness of mosquitoes to plas- modia}

The refractoriness to plasmodium is indicated by the failure of oocysts to develop in the mosquito midgut. It is a innate feature of each species of mosquito, and depends both on the genetic background of the insect and of the parasite. Even within species considered as highly susceptible to plasmodium infection such as A. gambiae, 
different degrees of susceptibility are found (Taylor 1999, Luckart et al. 2003), depending on the particular way they interact with malaria parasite (Lambrechts et al. 2005, Hurd 2007). Indeed, Luckart et al. (2003) found that the frequency of natural plasmodium infection in field-collected anophelines is associated with allelic polymorphisms in nitric oxide synthase and cecropin, two molecules involved in mosquito defense against malaria parasites.

The small percentage of infected A. gambiae collected in areas of high prevalence of malaria (Greenwood \& Mutabingwa 2002) may be a reflex of some degree of refractoriness of the most important vector of malaria in the world. In fact, Menge et al. (2006) identified two quantitative trait loci controlling refractoriness to P. falciparum in natural A. gambiae collected at an area of high transmission of malaria. The two loci explain $\sim 20 \%$ of the variation in parasite density, suggesting that other not-yet-identified loci may be involved.

The understanding of the factors involved in mosquito refractoriness to plasmodium is extremely important for malaria control. Even in areas with intense transmission, the probability that a mosquito becomes infected is generally low (Taylor 1999). Furthermore, the probability of infection is generally low even when mosquitoes are artificially fed on a blood meal known to contain infectious gametocytes (Gouagna et al. 1998). This finding can have several explanations: (1) mosquitoes fail to pick up infective gametocytes; (2) transmission-blocking immunity in the human hosts prevents the development of parasite within the mosquito (Targett 1988); (3) parasites are cleared by mosquitoes that mount a sufficiently effective immune response (Dimopoulos 2003); (4) development by the parasite of mechanisms to evade or to block the mosquito defenses (Carton et al. 2005); (5) genetic incompatibility between mosquito and plasmodium that impedes the development of the infection (Lambrechts et al. 2005).

A relatively few number of mosquito species display ideal biological conditions to bear the development of malaria parasites. However, even these species are able to become refractory, as shown by Collins et al. (1986). If this possibility is also demonstrated in natural conditions, it will represent an important mechanism of adaptation of mosquitoes.

\section{Selection of mosquito genetic traits by plasmodia}

Several indirect findings suggest that plasmodia are able to shape mosquito genome and, hence, select genetic traits: (1) the limited genetic variation in laboratory colonies of mosquitoes as compared to that of natural populations (Norris et al. 2001), which are submitted to stronger selective constraints; (2) the correlation between certain immune gene allele frequencies in mosquitoes and their degree of exposure to infection (Luckart et al. 2003); (3) the presence of intraspecific nucleotide variation in A. gambiae (Morlais et al. 2004).

It was demonstrated that $16 \%$ of the euchromatic portion of the assembled genome of A. gambiae is composed of transposable elements (Holt et al. 2002). The recognition that genomes are dynamic systems capable of been influenced by transposons of different origins (Tu \& Coates 2004), which can be co-opted to perform critical biological functions in their host (Kidwell \& Lisch 2002) lead us to the speculation whether some of the transposons incorporated to the mosquito genome could be originated from its long-lasting association with plasmodium.

\section{ADAPTATION OF PLASMODIA TO MOSQUITOES}

\section{Strategies of plasmodium adaptation to the immune mosquito}

Survival and adaptation are basic tenets of all living systems. Hence, it is plausible to consider that the plasmodium has developed survival and adaptation strategies to counteract the mosquito reaction to its presence. However, this subject has not as yet been submitted to the attention it deserves and very few data are available.

The more compelling evidence that, during its sporogonic cycle, the plasmodium displays counteracting strategies is its ability to silence some genes activated during the immune response of the mosquito host. Indeed, it has been shown by linkage analysis a higher frequency of some gene silencing in infected mosquitoes, including the TEP1 (thioester-containing protein 1) (Blandin et al. 2004), the LRIM (leucine-rich repeat immune gene) and the APL1 (Anopheles Plasmodiumresponsive leucine-rich repeat 1) (Riehle et al. 2006).

\section{Improvement of plasmodium development in the mosquito}

It is expected as the result of a long association, due to the selective process, the genetic perfecting of the involved partners and hence, a better adaptation. This appears to be the case when it is compared the response of A. gambiae to its old fellow P. falciparum with that of the infection with rodent pathogen $P$. berghei. The infection by the unnatural species causes a smaller number of induced putative immune genes, which may indicate that the mosquito's immune surveillance system is more capable of sensing $P$. falciparum, or alternatively, $P$. berghei may in some way suppress the mosquito's immune response (Dong et al. 2006). Another difference between natural and unnatural infection of $A$. gambiae is the significantly higher permissiveness toward $P$. berghei than for P. falciparum. While P. berghei frequently produces more than 300 oocysts on the mosquito midgut epithelium, $P$. falciparum rarely produces more than two to five oocysts, either under laboratory conditions or in nature (Sinden et al. 2004).

\section{ADAPTATION OF MOSQUITOES TO HUMANS}

\section{Development of resistance to insecticides}

Pyrethroid-treated bednets are the mainstay of malaria control programs in sub-Saharan Africa, where malaria reaches its highest incidence and mortality. Pyrethroids are a class of fast acting and highly effective insecticides showing low mammalian toxicity levels. Currently no other insecticide class with similar efficacy and specificity is available for use on bednets (Müller 2007). Therefore the emergence of pyrethroid resistance threatens the successful use of insecticide-treated materials (Vulule et al. 1994, Awolola et al. 2002, Stump 
et al. 2004). Due to a process of selection, the mutated insecticide-resistant variants of mosquitoes survive and grow, whereas the non-mutated insecticide-sensitive variants will succumb.

Two main insecticide resistance mechanisms are recognized: (a) metabolic resistance due to alterations in the levels or activities of detoxification proteins, and (b) target site insensitivity due to different mutations. Alone or in combination, these mechanisms confer resistance, sometimes at an extremely high level, to all of the available classes of insecticides (Hemingway et al. 2002, 2004). Target site insensitivity to pyrethroids in A. gambiae is associated with a single point mutation, commonly referred to as knock-down resistance $(k d r)$. The $k d r$ allele leads to a modification of the voltagegated sodium channel protein resulting in reduced sensitivity to both DDT and pyrethroids (Martinez-Torres et al. 1998). Metabolic resistance is generally associated with mutations in three enzyme family genes: cytochrome P450 monooxygenases (P450s), carboxylesterases (COEs), and glutathione-S transferases (GSTs). A total of 111 putative P450s, 51 COEs, and 31 GSTs genes have been identified in A. gambiae (Ranson et al. 2002). Although these three enzyme families have been widely associated with insecticide detoxification, the role of individual enzymes remains largely unknown (Müller 2007).

Some insecticides, for instance DDT and permethrin, cause behavioral changes in the insect, including reduction of the rate of mosquito entry into houses, increase of the rate of early exit from houses, and induction of a shift in biting times (Mbogo et al. 1996, Mathenge et al. 2001). Furthermore, some mosquitoes have evolved thicker or altered cuticles, for reducing the insecticide penetration (Apperson \& Georghiou 1975).

On the evolutionary viewpoint, the acquisition of resistance to insecticides by mosquitoes represents a very tricky way to overcome a chemical constraint but, on the viewpoint of malaria control, it represents a disaster.

\section{Man-induced behavioral changes of mosquitoes}

It is possible to speculate that, since the emergence of humans in the planet, they have been a major driving force for mosquito's evolution due to the powerful constraints imposed by the alterations they caused in the biome. In fact, several adaptive changes, particularly in the behavior of mosquitoes, were the consequence of selective processes involving the survival of the fittest individuals.

In their natural ecosystem, anophelines live in a state of equilibrium with the environment. The density of the anthropophilic species is usually low in untouched forest areas (Tadei et al. 1998, Vittor et al. 2006), but it substantially increases upon the establishment of human settlements (Castro et al. 2006). This disequilibrium is due basically to an increased offer of feeding and more opportunities to breeding. It has been shown that even anthropophilic species of anophelines can change their feeding habits if their preferable source of blood is scarce (Trung et al. 2005). Thus, it can be speculated that even the highly anthropophilic species as A. gambiae in Africa, A. darlingi in America, and A. dirus in Asia, can survive in areas of low human density by feeding in animals.
The increase of breeding opportunities for the mosquito is a consequence of human intervention in the insect ecosystem, in the absence of proper planning and adequate infrastructure, including rural and peri-urban settlements, deforestation for agricultural, cattle-raising, mining, and lumbering projects, dams and irrigation projects, and the construction of roads and pipelines. After a period varying from about 5 years (McGreevy et al. 1989) to 10-15 years (Vittor et al. 2006) the ecological equilibrium is re-acquired and the risk of malaria transmission is substantially reduced or nullified (Tadei et al. 1998, Castro et al. 2006). However, this equilibrium is unstable and can be broken if some external factor threatens it (Póvoa et al. 2003).

Man-made ecological disturbances are good opportunities to allow mosquitoes to show their incredible capacity to adapt and survive against the odds. Hence, it has been shown that, when compelled to it, anophelines can bear to breed in highly organic polluted water (Chinery 1984, Mukhtar et al. 2003, Sattler et al. 2005), oviposit on moist soil, if flooded soil is not available (Minakawa et al. 2001), and survive extreme dryness (Omer \& Cloudsley-Thompson 1970, Charlwood et al. 2000, Koenraadt et al. 2003). Except for the adaptation to antimalarial drugs, the genetic background of the process of mosquito adaptation to other man-induced situations are mostly unknown.

The existence of a wide intraspecific variety of mosquito behavioral patterns has been recognized (Trung et al. 2005). Since the environment influences the shaping of mosquito genome (Land 2003, Marinotti et al. 2006), it is tempting to speculate whether some ill-characterized variants of Anopheles such as the cryptic species complexes (Tadei \& Thatcher 2000) could have arisen as a consequence of man-made influences.

\section{COADAPTATION AND MALARIA}

\section{What is coadaptation?}

The meaning of the word 'adaptation' is very ambiguous, because the same term is used for several different biological concepts. It is used to refer to the class of relationships of an organism to its environment, or may refer to the state when we say that an organism is adapt to living in a particular habitat, finally it can denote the properties conferred upon the organism by the process (Ghiselin 1966). In the present context, adaptation will be used with the meaning of a biological process that evolved over a period of time as a consequence of natural selection characterized by functional, behavioral or structural changes that lead to a better fitness, and can affect either the phenotype or the genotype (Horwitz \& Wilcox 2005, West-Eberhard 2005). Hence, coadaptation is a process of mutual adaptation involving two or more partners.

\section{rules and rationale of coadaptation}

Coadaptation is a common feature of all host-parasite relationships and is constrained by time and space. As closer and longer the association between the partners more critical coadaptation is. Since no parasite is best at infecting all hosts, and no host is best at resisting 
all parasites (Lambrechts et al. 2005), the success of infection - that means adaptation - depends on the specific combination of the partners, the relationships being governed by genotype by genotype interactions (Horwitz \& Wilcox 2005), in such way that individual hosts are resistant to only a portion of the parasite genotypes and, reciprocally, individual parasites can infect only particular host genotypes (Schmid-Hempel \& Ebert 2003).

Coadaptation is a dynamic process and the established equilibrium is continuously kept under check. In fact, highly virulent parasites that have lost their virulence upon adaptation may eventually reacquire their ability to harm the host (Ewald 1983). These shifts occur at different temporal scales, either within the generation time of the host, or over perhaps extraordinarily long periods in an evolutionary sense (Horwitz \& Wilcox 2005).

Summers et al. (2003) have characterized, by modeling, some important aspects of coadaptive associations. Host-parasite interaction can produce an escalating "arms race" in which phenotypic traits under polygenic control undergo reciprocal increases over evolutionary time. This occurs relatively rapidly, depending on the selective pressures and costs associated with each response. Also, the much shorter generation time and faster growth rate of a parasite population in relation to that of its host indicate that 'evolutioning time' for a parasite is often only 'ecological time' for the host (Horwitz \& Wilcox 2005). Indeed, within a human lifetime, most bacteria can present over 1 million generations and, therefore, their ability to evolve and develop strategies of adaptation is overwhelmingly higher than that of humans.

The host-parasite relationship can involve co-existence at the individual or population level, even though it involves the diversion of resources by the parasite from the host that could otherwise be used for the host's growth, maintenance or reproduction. How this asymmetrical relationship could possibly persist becomes apparent considering the ecosystem-level interactions. When viewed as part of an ecosystem, the parasitized host is subject to numerous other interactions that lead to benefits, no apparent benefits, or harm or disbenefits to it (Horwitz \& Wilcox 2005).

\section{Coadaptation in malaria}

To grasp a complex system it is necessary first to acknowledge its complexity and second to analyze its parts in an attempt to understand the whole. Malaria is the result of the interactions of three highly complex and dynamics systems: the human, the plasmodium and the mosquito. Each one of these systems presents peculiar characteristics, including different evolving times, survival strategies, biological and biochemical complexities, and also different features of organization and regulatory mechanisms. Also, the degree of dependence of the three systems is rather different: although the plasmodium strictly depends both on the vertebrate and the invertebrate host for its development, the mosquito depends on the human feeding for maturing its eggs, but does not depend on the plasmodium, the human being depends neither on the plasmodium nor on the mosquito. Another important point to be raised is that, notwithstanding their degrees of dependence on other systems, the three systems are self-regulated and, as a consequence of selective processes that have been occurring since their emergence, they all present a high ability to adaptation, whose degree probably depends on their phylogenetic age. Since it is composed by three complex systems, the system HPM, where malaria arises, could be considered as a super-complex system.

The Figure depicts the varieties of coadaptive interactions that occur in the super system HPM. The interface A comprises the coadaptive phenomena involving human and plasmodium, which are governed, in a natural scenario, by the interactions of the parasite with human immune system, and, in an artificial scenario, by the reactions of plasmodium to antimalarial drugs. In interface $B$, all coadaptive interactions between plasmodium and the mosquito immune system take place, including the strategies used by the parasite to adapt to or escape from the immune system of the insect. Interface $C$ comprises the natural interactions between human and mosquito immune systems, but also the response of mosquitoes to some artificial constraints imposed by humans, as the insecticides. Finally, interface $D$ represents the confluence of all coadaptive phenomena that occur in the system, and it is where equilibrium is attained and should be sought when broken.

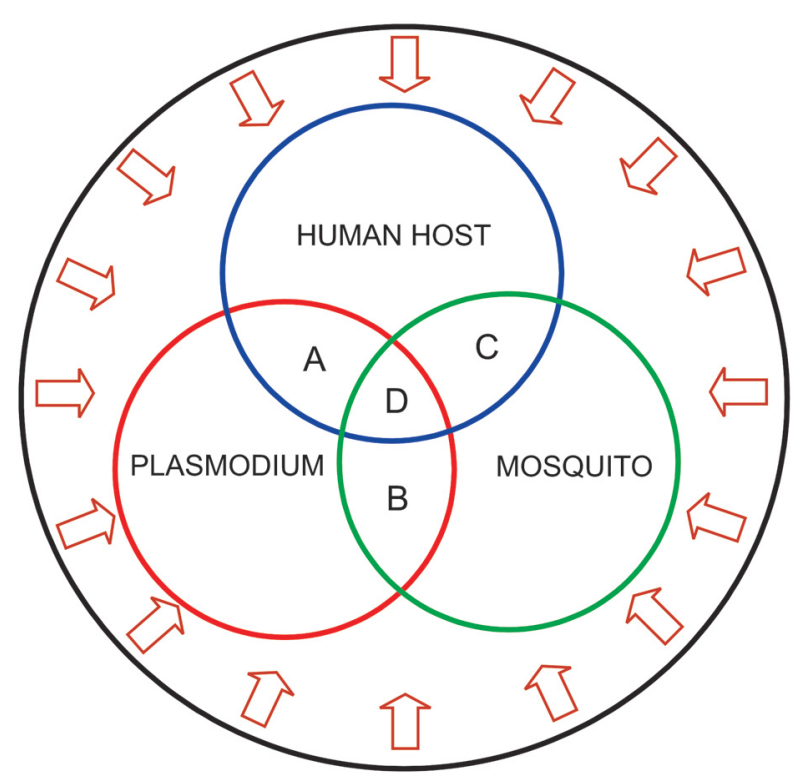

Malaria is the result of the association of three highly complex and dynamic systems - the human host, plasmodium and the mosquito - all influenced by the environment (arrows). Coadaptive connections are established at the interfaces and involve genetic and epigenetic phenomena and, probably, the exchange of infectrons (genes or gene sequences). Interface $A$ comprises the binomial human $\leftrightarrow$ plasmodium and encompasses the coadaptive strategies related to the interplay of plasmodium with the human immune system. Interface $B$ represents the binomial plasmodium $\leftrightarrow$ mosquito and includes the interplay of plasmodium with the mosquito immune system. Interface $C$ comprises the binomial mosquito $\leftrightarrow$ human and the interplay between their immune systems. Interface $D$ represents the confluence of all coadaptive phenomena that occur in the system, and where equilibrium is attained and should be sough when broken. Coadaptive strategies for malaria control act on interfaces A, B, and C, whereas panadaptive strategies act on interface $\mathrm{D}$ (see next Section). 
Coadaptation aims at the acquisition of mutual equilibrium between the involved parts. However, this represents a process, and involves occasional periods of instability for adjustments. A major component of the adaptive process in the system HPM is the particular way the immune system of both the vertebrate and the invertebrate hosts react to plasmodium. An excessive immune response can affect the parasite and eventually destroy it but, on the other hand, may harm both the human host (Maitland \& Marsh 2004, Mackintosh et al. 2004), and the mosquito (Schmid-Hempel 2003). As put by Boëte (2005), avoiding the burden of infection benefits the parasite and the host, but an excessive immune response might be detrimental for both. It is important to consider that coadaptation involves the coexistence both at the individual and population level and, even though it sometimes involves the diversion of resources by the parasite from the host that could otherwise be used for the host's growth, maintenance or reproduction. In evolutionary terms, therefore, there are good reasons why we should see parasites as conveying a selective advantage to their hosts under certain circumstances (Woolhouse et al. 2002, Horwitz \& Wilcox 2005).

The rules and mechanisms governing the interactions between the components of the system HPM are mostly unknown. It can be postulated that the forces that lead to coadaptation act at their interfaces and involve a vast array of genetic and epigenetic phenomena. These include gene activation, gene mutation, epigenetic alterations and, possibly, exchange of genetic material between the partners of the association. Several interactions depends simply on gene expression induced in humans by plasmodia or mosquitoes, including the activation of human immune system, activation of hepatocytes, and endothelial cells, synthesis of protein as antibodies and cytokines, synthesis of oxygen radicals, and apoptosis of host cells (Ndungu et al. 2005, Engwerda \& Good 2005, Wykes et al. 2007). Cell activation is also present in mosquitoes upon contact with human or parasite products (Hurd 2007). There are also evidence that both gametocytogenesis (Gardiner et al. 2005) and sporogony (Vaughan 2007) are induced by host signals.

A second mechanism of genetic interactions between the components of the system HPM involves gene mutation. This occurrence has been widely demonstrated in association with development of plasmodium resistance to antimalarial drugs (Das \& Dash 2007), of mosquitoes to insecticides (Martinez-Torres et al. 1998), and of refractoriness of mosquitoes to plasmodia (Lambrechts et al. 2005, Menge at al. 2006). Recurrent gene amplification has also been associated to development of antimalarial drug resistance by plasmodium (Nair et al. 2007)

Epigenetic alterations in the genome of components of the system HPM have been recently demonstrated. For instance, heterochromatin silencing and histone acetylation have been described in plasmodium genome associated to the control of var genes transcription and antigenic variation (Deitsch et al. 2001a, Duraisingh et al. 2005, Freitas-Júnior et al. 2005). Interestingly, these alterations do not involve modification in nucleotide sequence but, nevertheless, are able to be transmitted to the progeny (Blewitt et al. 2006, Whitelaw \& Whitelaw 2006). In fact, Chookajom et al. (2007) described antigenic variation of plasmodium related to chromatin memory that includes methylation of histone.

Infectrons are recognized inducers of epigenetic alterations of genomes (Doerfler 2005). This is a collective denomination for genes or gene sequences capable to invade host genomes and cause alteration of their structure or functions (Tosta 2001). Retroelements are the best known infectrons in human genome. It is estimated that approximately $50 \%$ of the human genome is composed of such repetitive sequences (Lander et al. 2001). This is likely a conservative estimate as many other repeat-generated regions have degenerated beyond recognition (Hedges \& Batzer 2005). The retroelements found in human genome are divided into three main categories: the most frequent are Alu elements (SINE) with an estimated 1 million copies per human genome (Shedlock et al. 2004), L1 elements (LINE), which comprise about $17 \%$ of the genome (Ustyogova et al. 2006), and endogenous retroviruses with an estimated 98,000 copies per genome (Katzourakis et al. 2005). Apart from epigenetic reprogramming, infectrons are able to shape their host genomes by means of exon shuffling, gene conversion, and alternative gene splicing (Hedges \& Batzer 2005).

There is, as yet, few evidence of transfer of infectrons between the components of the system HPM. Retroelements of primate origins have been detected in the mosquito genome (Biedler \& Tu 2003, Barnes et al. 2005, Crainey et al. 2005), and possibly also in the plasmodium genome (Dhar et al. 1998, Deitsch et al. 2001b). More recently, Cordery et al. (2007) characterized a functional macrophage-migration inhibitory factor homologue produced by $P$. falciparum-infected erythrocytes. The possibility that this product is codified by a gene taken up from human host, as happens with other infectious agents (McFadden \& Murphy 2000, Seet et al. 2003, Hughes \& Friedman 2005) cannot be ruled out.

\section{COADAPTIVE STRATEGIES FOR MALARIA CONTROL}

\section{Why coadaptive strategies?}

Malaria control has traditionally relied on the use of insecticides for vector control and on antimalarial drugs for treating malaria episodes. This combined approach proved remarkably effective in many settings, particularly in Europe and North America, whereas malaria continues to represent a huge burden in sub-Saharan Africa, and also in Asia and South and Central America. The reasons for the failure of the global programme for malaria eradication, launched by the World Health Organization in the $1950 \mathrm{~s}$, are complex but include the resistance $P$. falciparum has developed to all currently available classes of antimalarial drugs, with the important exception of the artemisinin compounds (White 2006), and the resistance of mosquitoes to a wide range of insecticides (Pates \& Curtis 2005). In spite of some initiatives of malaria control (e.g. WHO's Roll Back Malaria), malaria morbidity and mortality have worsened (Yamey 2004). 
The presently available strategies for malaria control rely on the assumption that the way to get round it is by fighting malaria parasites with drugs and the anopheline vectors with insecticides (Phillips 2001, Shiff 2002). These approaches do not take into account that malaria is associated to adaptive forces involving the human host, the plasmodium and the anopheline vector, as showed in this article. Moreover, both plasmodia ( $\mathrm{Su}$ et al. 2003, Escalante et al. 2005) and mosquitoes (Feyereisen 2006) preceded, for an extremely long while, the emergence of human beings in the planet, and hence present very long 'evolutioning times' (Horwitz \& Wilcox 2005). In addition, the fact that they both have very short lifetimes in comparison to that of humans allow them to present several-fold more generations during a human's lifetime, this means adaptation and evolution. Therefore, it can not be ruled out that the limited usefulness of the present strategies for malaria control is due to a conceptual framework that ignores the natural relationships between the three actors of malaria's drama.

A novel set of strategies is proposed based on the reality of the adaptive forces that command the relationships among the human host, malaria parasite, and the mosquito vector, within a conceptual framework of a ecological-evolutionary complex system. The adaptive strategies for malaria control are endowed with the following features: (1) based on the Nature's lessons regarding malaria and the relationships of its three components; (2) adaptation instead of destruction; (3) an integrated approach.

\section{Coadaptive malaria vaccines}

The results of the first trial of a candidate malaria vaccine, prepared by Étienne and Edmund Sérgeant at the Institut Pasteur of Tunis, were published nearly one century ago. Since then, over 100 different formulations of candidate malaria vaccines have been developed and tried, 34 of then in humans (Table IV), but none could so far be established as an adequate public health tool. The most promising candidate, the pre-erythrocytic subunit vaccine RTS,S, which consists of P. falciparum CSP polypeptide fused to the recombinant $S$ antigen of hepatitis B virus, tested in Mozambican children aged one to four years old, reduced the risk of infection by $45 \%$ over the first six months of observation compared with children that received a control vaccine, and reduced the prevalence of infection by $29 \%$ over an 18-month follow up period (Alonso et al. 2004, 2005). However, as happens with other sporozoite-based canditated vaccines, the immunity was relatively short-lived (Matuschewski 2006b) and, at the end of the trial, cumulative data showed that the number of infections was virtually indistinguishable in vaccinees and control group.

Several reasons for the difficulties to develop efficacious malaria vaccines have been raised, including the high antigenic and biological complexity of the parasite; the lack of adequate models for the infection; the insufficient understanding of the nature of anti-plasmodial immunity; the unavailability of reliable parameters and tests for assessing protective immunity; the difficulty
TABLE IV

Candidate malaria vaccines under development or test

Pre-erythrocytic stage: 33 (CSP, TRAP, LSA-1, LSA-2)

Asexual erythrocytic stage: 50 (MSP-1, MSP-2, MSP-3, MSP-4, MSP-5, AMA-1, EBA-175, GLURP, EBP-2, RAP-2, GPI, PfEMP-1)

Sexual erythrocytic stage: 8 (PvS25, PvS28, PfS25, PfS28, PfS230)

Multistage: 11

Total: $102^{a}\left(34^{b}\right.$ reached or completed clinical trial)

a: 79 Plasmodium falciparum and 23 P. vivax; $b$ : 32 P. falciparum and 2 P. vivax. Adapted from:http://www.who.int/vaccine_research/ documents/en/malaria_table.pdf and Malaria Vaccine Technology Roadmap Draft, July 2005, and Herrera et al. (2007).

to select relevant antigens to be included in vaccine formulations amongst the vast array of the proteins produced by the plasmodium genome, composed of 5268 genes (Gardner et al. 2002); the genetic restriction of the target-population; and the great challenge of protecting a population with an intensive present and past contact with malaria parasite.

Notwithstanding the technical and scientific difficulties that have been faced in the quest for a malaria vaccine, a very important point has been frequently neglected: what is to be expected of malaria vaccination? The usually expected outcome has been the reduction of local malaria prevalence. This objective is based on the consideration that, upon proper stimulation by vaccine, the immune system will be able either to get rid of the actual infection and/or to prevent new ones. This assumption, which emerges from all current issues of vaccinology, is based on the idea that the function of the immune system is to keep the organism free of noxious agents. This point was expressed by Bachmann and Kopf (2002), to whom "the immune system is an efficient army designed to fight invading pathogens... hence, the primary objective of the immune system is destruction". If this were the real aim of the immune system, its efficiency should be considered as very low since it is not capable to get rid of the thousands of species of microorganisms that live within our organism. For instance, the human gut is inhabited by a community of $10^{14}$ bacteria, belonging to over 400 species, and whose collective genome ("microbiome") contains at least 100 times as many genes as our own genome (Gill et al. 2006, Ley et al. 2006). In addiction, an estimated 1200 different viral genotypes were characterized by metagenomic analyses of human feces (Breitbart et al. 2003). The real function of the immune system is to keep the integrity of the organism, and for fulfilling this aim it reacts to infectious agents and develops different strategies of adaptation to them, that eventually lead to the partial or total destruction of the microorganism. Therefore, the bellicose view of the immune system has no support in the reality that we live in equilibrium with our microbiota, not in spite of the immune system, but because of it (Tosta 2001, Lenzi \& Vannier-Santos 2005). 
If the expected outcome of malaria vaccination shifts from protecting against the parasite to surviving with the parasite, but without experiencing the noxious effects it can cause, a novel concept is introduced: the coadaptive vaccine. The conceptual framework for coadaptive malaria vaccines relies on the following assumptions: (1) the basic function of the immune system is adaptation not destruction; (2) after some time in contact with malaria parasite, the vast majority of people living in areas of malaria transmission reach a state of equilibrium: they harbor the parasite (or several genotypes of it), although present minimal or no manifestation of its presence; (3) if the (whole) living parasite is not able to induce sterile immunity, why would a part of it (a vaccine) manage to do it?; (4) the lessons of Nature teach us that all biological phenomena involving the system human-plasmodiummosquito are based on adaptation (see the first part of this article); (5) after nearly one century of attempts to develop a protective malaria vaccine, when over 30 of them, submitted to clinical trials, attained results below the expectations, a novel paradigm for malaria vaccination should be earnestly sought. Indeed, the need to adopt changes in the strategies of malaria vaccine testing and development has been considered by the scientific community involved with malaria control (see Matuschewski 2006b, Snounou \& Rénia 2007).

What would a coadaptive malaria vaccine be? The aim of a coadaptive malaria vaccine would be to prevent both parasite overgrowth and the over-stimulation of the immune system, the two causes of mortality in malaria. It is expected that, if the inhabitants of areas of malaria transmission were kept with low parasitemias during the first episodes of malaria, the further infections will act as boosters of the immune response, and host-parasite equilibrium, the most common outcome of the infection, will be attained in the absence of the clinical-pathological manifestations of malaria. The data of Pombo et al. (2002), showing that efficient anti-plasmodial immunity is developed after the administration of ultralow doses of P. falciparum-infected erythrocytes, give support for this proposal.

The outcome to be attained with the application of coadaptive malaria vaccines would shift from decreasing malaria prevalence to reduce or abolish its morbidity and lethality. Important insights on the immunological bases for developing coadaptive vaccines should be sought on the in-depth investigation of those individuals with asymptomatic infections, particularly on the factors responsible for the state of equilibrium between the host and the parasite. It is very important to characterize the factors and mechanisms involved in the induction and the regulation of anti-parasite immune response in those individuals.

A group of four institutions, headed by the World Health Organization, launched in December 2006 the Malaria Vaccine Technology Roadmap, a global strategy for developing an effective malaria vaccine by 2025 (WHO 2006). Intuitively, the effective vaccine that is been targeted is a 'coadaptive vaccine', endowed with a protective efficacy of more than $80 \%$ against clinical disease, and not infection. Unfortunately, the adopted priorities and strategies for reaching this outcome are paradoxically those directed for the development of a classical 'destructive' (prevalence-based) vaccine, and not of a 'coadaptive' (disease-based) vaccine.

\section{Panadaptive strategies}

It is clear that the control of such a pervasive condition as malaria, which involves three highly dynamic and complex components - the human host, the plasmodium and the mosquito - cannot be adequately tackled with simple and partial measures. Comprehensive and integrated approaches need to be adopted aiming at acting effectively on the three components involved in the disease, and has also to take into account the influence represented by the environment. Coadaptive strategies for malaria control have to be, by their own nature, integrated measures, since they have to be based on the attempt to establish or improve the equilibrium between the components of the system 'human-plasmodium-mosquito'. However, their efficiency will substantially improve if coadaptive strategies targeting at each two components of the system (human-plasmodium, plasmodium-mosquito and mosquito-human) are all applied in the form of panadaptive strategies (see Figure).

The principles commanding panadaptive strategies are based on: (1) the fact that the relationships involving the components of the system 'human-plasmodium-mosquito' lead to adaptation, and that disease and death are consequences of misadaptation or non-adaptation; (2) plasmodia and mosquitoes have been submitted to selective pressure for an extremely long while and are, therefore, endowed with the capacity to resist to all natural (immunity) and artificial (drugs, insecticides, vaccines) measures aiming at destroying them; (3) the most efficient way to tackle with complex systems (e.g. 'human-plasmodium-mosquito'), whose disequilibrium give rise to disease, is by trying to maintain their equilibrium, both the internal (between their intrinsic components), and the external one (with the environment), through coordinated and comprehensive approaches.

Coadaptation and, as a consequence, panadaptation that is the assemblage of the processes of coadaptation, involve the prolonged association of the components of the system HPM, with minimal harm between them. This association, by its turn, depends on the balanced interactions of the plasmodium with the immune system of both human and mosquito hosts. Some conditions are necessary for the acquisition and maintenance of the equilibrium between the immune system and plasmodium: (1) host immune response has to be induced, since without immune response no coadaptation is attained; (2) the immune response has to be sustained and efficient enough to avoid plasmodium overgrowth; (3) the immune response should not destroy all parasites; (4) the immune response has to be well controlled in order to not harm the host. These conditions are mostly influenced by antimalarial drugs, and should also be taken into account for the development of coadaptive malaria vaccines (see above).

The timing for the administration of an antimalarial drug should ideally be delayed enough to allow for the 
induction of host immune response by the parasite, but without posing unnecessary risks for the patient's health. It was showed in an experimental model that the precocious administration of antimalarial drugs prevents the induction of cross-protection to a new challenge with parasite (Legorreta-Herrera et al. 2004). It is also important to consider that nearly all antimalarial drugs display immunodepressive effects (Muniz-Junqueira \& Tosta 2007) and, therefore, their excessively precocious administration can somehow impair the development of the immune response. The fact that slowly eliminated antimalarial drugs exert a selective pressure on plasmodium and facilitate the emergence of drug-resistant variants (White 2006) should also be considered.

A new approach for the prevention of malaria in pregnant women and children has been recently adopted: the intermittent preventive treatment (Greenwood 2006, Schellenberg et al. 2006). It consists in the administration of a full course of an antimalarial treatment to a population at risk at specified time points regardless of whether or not they are known to be infected. This preventive treatment approach was able to a $40 \%$ reduction in overall child mortality in some highly endemic African areas (Greenwood 2006). However, the possibility that any form of chemoprevention could impair the development of immunity by treated individuals represents a real concern. Indeed, an increase in clinical attacks of malaria was observed in children who had previously received chemoprophylaxis during the year after chemoprophylaxis was stopped (Greenwood et al. 1995). Greenwood (2006) points out that reduction of the level of exposure to malaria below a critical point, by any means, will impair the development of naturally acquired immunity to the infection, but it is not known what the critical level is. It is possible that a modest exposure to plasmodium may prove more effective at inducing immunity than massive exposure. Thus, a study with Gambian children showed that those who received chemoprophylaxis had greater cellular immune responses to malaria antigens than control children, although they had lower antibody concentrations (Otoo et al. 1989). The findings of sustained protection against malaria seen in children who had received intermittent preventive treatment in Tanzania (Schellenberg et al. 2005), and the no significant increase in the incidence of malaria in Senegalese children submitted to this regimen (Cissé et al. 2006) indicate the absence of an important impairment of antimalarial immunity in these cases. The finding that malaria chemoprophylaxis does not alter the immune response to most vaccines (Rosen \& Breman 2004) supports this possibility.

\section{CONCLUSIONS}

A famous prayer, falsely attributed to Saint Francis of Assisi (Boff 1999), says that 'by giving, we receive'. So is coadaptation. It involves a compromise between the 'giving' and the 'receiving', and conveys mutual benefits. Adaptation and coadaptation are general rules of Nature and involves all living systems. The system HPM could not be an exception. All phenomena implicated in the multiple interactions among the three components of the system HPM involve coadaptation. Malaria can be considered as an expression of disequilibrium of this system. So, it can be asked, why the adopted measures for malaria control do not consider this reality? Why do current measures rely on destruction, instead of adaptation? A possible answer will certainly include the anthropocentric attitude of man in relation to Nature. It is an instinctive reaction trying to destroy whatever is considered as a threat, and plasmodia and mosquitoes are real threats. However, human beings have also reason, to modulate the instincts. And, it is possibly considered unreasonable to base malaria control on the destruction of plasmodia and mosquitoes, species extremely much older and, therefore, more selected and adaptable, than human beings. This essay presents an alternative view for malaria control, based on coadaptation.

\section{ACKNOWLEDGEMENTS}

For the last 40 years, I have been trying to understand what malaria is. This review contains my present insights. I express my gratitude for this construction to: those who suffer of malaria, while waiting for coadaptation; the authors, who nourished me of informations, and the musicians, who nourished me of inspiration; the Brazilian Ministry of Education (Portal Periódicos) and the American National Library of Medicine (PubMed), which allowed me to gather over 5000 scientific articles that served as a basis for this review; Henrique Lenzi, for the valuable and constant breakthroughs; Luzia Guimarães, a love's emanation.

\section{REFERENCES}

Ackerman H, Usen S, Jallow M, Sisay-Joof F, Pinder M, Kwiatkowski DP 2005. A comparison of case-control and family based association methods: the example of sickle-cell and malaria. Ann Hum Genet 69: 559-565.

Agarwal A, Guindo A, Cissoko Y, Taylor JG, Coulibaly D, Kone A, Kayentao K, Djimde A, Plowe CV, Doumbo O, Wellems TE, Diallo D 2000. Hemoglobin C associated with protection from severe malaria in the Dogon of Mali, a West African population with a low prevalence of hemoglobin S. Blood 96: 2358-2363

Alonso PL, Sacarlal J, Aponte JJ, Leach A, Macete E, Milman J, Mandomando I, Spiessens B, Guinovart C, Espasa M, Bassat Q, Aide P, Ofori-Anyinam O, Navia MM, Corachan S, Ceuppens M, Dubois MC, Demoitié MA, Dubovsky F, Menéndez C, Tornieporth N, Ballou WR, Thompson R, Cohen J 2004. Efficacy of the RTS,S/AS02A vaccine against Plasmodium falciparum infection and disease in young African children: randomised controlled trial. Lancet 364: 1411-1420.

Alonso PL, Sacarlal J, Aponte JJ, Leach A, Macete E, Aide P, Sigauque B, Milman J, Mandomando I, Bassat Q, Guinovart C, Espasa M, Corachan S, Lievens M, Navia MM, Dubois M-C, Menéndez C, Dubovsky F, Cohen J, Thompson R, Ballou WR 2005. Duration of protection with RTS,S/AS02A malaria vaccine in prevention of Plasmodium falciparum disease in Mozambican children: single-blind extended followup of a randomized controlled trial. Lancet 366: 2012-2018.

Alves FP, Durlacher RR, Menezes MJ, Krieger H, Silva LHP, Camargo EP 2002. High prevalence of asymptomatic Plasmodium vivax and Plasmodium falciparum infections in native Amazonian populations. Am J Trop Med Hyg 66: 641-648.

Anderson TJC, Haubold B. Williams JT, Estrada-Franco JG, 
Richardson L, Mollinedo R, Bockarie M, Mokili J, Mharakurwa S, French N, Whitworth J, Velez ID, Brockman AH, Nosten F, Ferreira MU, Day KP 2000. Microsatellite markers reveal a spectrum of population structures in the malaria parasite Plasmodium falciparum Mol Biol Evol 17: 1467-1482.

Andrade AL, Martelli CMT, Oliveira RM, Arias JR, Zicker F, Pang L 1995. High prevalence of asymptomatic malaria in gold mining areas in Brazil. Clin Infec Dis 20: 475.

Apperson CS, Georghiou GP 1975. Mechanisms of resistance to organophosphorus insecticides in Culex tarsalis. J Ecol Biochem 68: 63-78.

Asada H 2007. Hypersensitivity to mosquito bites: A unique pathogenic mechanism linking Epstein-Barr virus infection, allergy and oncogenesis. J Dermatol Sci 45: 153-160.

Asada H, Saito-Katsuragi M, Niizeki H, Yoshioka A, Suguri S, Isonokami M, Aoki T, Ishihara S, Tokura Y, Iwatsuki K, Miyagawa S 2005. Mosquito salivary gland extracts induce EBV-infected NK cell oncogenesis via CD $4^{+} \mathrm{T}$ cells in patients with hypersensitivity to mosquito bites. J Invest Dermatol 125: 956-961.

Awolola TS, Brooke BD, Hunt RH, Coetzee M 2002. Resistance of the malaria vector Anopheles gambiae s.s. to pyrethroid insecticides in South-western Nigeria. Ann Trop Med Parasitol 96: 849-852.

Bachmann MF, Kopf M 2002. Balancing protective immunity and immunopathology. Curr Opin Immunol 14: 413-419.

Barnes MJ, Lobo NF, Coulibaly MB, Sagnon NF, Costantini C, Besansky NJ 2005. SINE insertion polymorphism on the X chromosome differentiates Anopheles gambiae molecular forms. Insect Mol Biol 14: 353-363.

Beet EA 1946. Sickle cell disease in the Balovale district of Northern Rhodesia. East Afr Med J 23: 75-86.

Biedler J, Tu Z 2003. Non-LTR retrotransposons in the African malaria mosquito, Anopheles gambiae: unprecedented diversity and evidence of recent activity. Mol Biol Evol 20: 1811-1815.

Blandin S, Levashina EA 2004. Mosquito immune responses against malaria parasites. Curr Opin Immunol 16: 16-20.

Blewitt ME, Vickaryous NK, Paldi A, Koseki H, Whitelaw E 2006. Dynamic reprogramming of DNA methylation at an epigenetically sensitive allele in mice. PLoS Genet 2: e49.

Boëte C 2005. Malaria parasites in mosquitoes: laboratory models, evolutionary temptation and the real world. Trends Parasitol 21: 445-447.

Boff L 1999. A Oração de São Francisco, 7a ed., Sextante, Rio de Janeiro.

Bray PG, Martin RE, Tilley L, Ward SA, Kirk K, Fidock DA 2005. Defining the role of PfCRT in Plasmodium falciparum chloroquine resistance. Mol Microbiol 56: 323-333.

Breitbart M, Hewson I, Felts B, Mahaffy JM, Nulton J, Salamon P, Rohwer F 2003. Metagenomic analyses of an uncultured viral community from human feces. J Bacteriol 185: 6220-6223.

Calvo E, Mans BJ, Andersen JF, Ribeiro JMC 2006a. Function and evolution of a mosquito salivary protein family. J Biol Chem 281: 1935-1942.

Calvo E, Phama VM, Lombardo F, Arca B, Ribeiro JMC 2006b. The sialotranscriptome of adult male Anopheles gambiae mosquitoes. Insect Bioch Mol Biol 36: 570-575.

Carter R, Mendis KN 2002. Evolutionary and historical aspects of the burden of malaria. Clin Microbiol Rev 15: 564-594.

Carton Y, Nappi AJ, Poirie M 2005. Genetics of anti-parasite resistance in invertebrates. Dev Comp Immunol 29: 9-32.

Castro MC, Monte-Mór RL, Sawyer DO, Singer BH 2006. Malaria risk on the Amazon frontier. Proc Natl Acad Sci USA 103: 2452-2457.

Charlwood JD, Vij R, Billingsley PF 2000. Dry season refugia of malaria-transmitting mosquitoes in a dry savannah zone of east Africa. Am J Trop Med Hyg 62: 726-732.

Chinery WA 1984. Effects of ecological changes on the malaria vectors Anopheles funestus and the Anopheles gambiae complex of mosquitoes in Accra, Ghana. A J Trop Med Hyg 87: 75-81.

Chookajorn T, Dzikowski R, Frank M, Li F, Jiwani AZ, Hartl DL, Deitsch KW 2007. Epigenetic memory at malaria virulence genes. Proc Natl Acad Sci USA 104: 899-902.

Christophides GK 2005. Transgenic mosquitoes and malaria transmission. Cell Microbiol 7: 325-333.

Cissé B, Sokhna C, Boulanger D, Milet J, BâEH, Richardson K, Hallett R, Sutherland C, Simondon K, Simondon F, Alexander N, Gaye O, Targett G, Lines J, Greenwood B, Trape J-F 2006. Seasonal intermittent preventive treatment with artesunate and sulfadoxine pyrimethamine prevents malaria in Senegalese children. Lancet 367: 659-667.

Collins FH, Sakai RK, Vernick KD, Paskewitz S, Seeley DC, Miller LH, Collins WE, Campbell CC, Gwadz RW 1986. Genetic selection of a Plasmodium-refractory strain of the malaria vector Anopheles gambiae. Science 234: 607-610.

Cordery DV, Kishore U, Kyes S, Shafi MJ, Watkins KR, Williams TN. Marsh K, Urban BC 2007. Characterization of a Plasmodium falciparum macrophage-migration inhibitory factor homologue. J Infect Dis 195:905-912.

Coura JR, Suárez-Mutis M, Ladeia-Andrade S 2006. A new challenge for malaria control in Brazil: asymptomatic Plasmodium infection - A Review. Mem Inst Osw Cruz 101: 229-237.

Crainey JL, Garvey CF, Malcolm CA 2005. The origin and evolution of mosquito APE retroposons. Mol Biol Evol 22: 2190-2197.

Das A, Dash AP 2007. Evolutionary paradigm of chloroquineresistant malaria in India. Trends Parasitol (in press)

Deitsch KW, Calderwood MS, Wellems TE 2001a. Malaria. cooperative silencing elements in var genes. Nature 412: 875-876.

Deitsch KW, Carlton JMR, Wootton JC, Wellems TE 2001b. Host sequences in Plasmodium falciparum and Plasmodium vivax genomic DNA: horizontal transfer or contamination artifact? FEBS Let 24603: 1-2.

Demeure CE, Brahimi K, Hacini F, Marchand F, Péronet R, Huerre M, St.-Mezard P, JF Nicolas, Brey P, Delespesse G, Mécheri S 2005. Anopheles mosquito bites activate cutaneous mast cells leading to a local inflammatory response and lymph node hyperplasia. J Immunol 174: 3932-3940.

Dhar A, Gupta S, Sharma YD 1998. Alu elements in a Plasmodium vivax antigen gene. FEBS Let 423: 193-197.

Dimopoulos G 2003. Insect immunity and its implication in mosquito-malaria interactions. Cell Microbiol 5: 3-14. 
Doerfler W 2005. On the biological significance of DNA methylation. Biochemistry (Moscow) 70: 505-524.

Dong Y, Aguilar R, Xi Z, Warr E, Mongin E, Dimopoulos G 2006. Anopheles gambiae immune responses to human and rodent Plasmodium parasite species. PLoS Pathog 2: e52.

Duraisingh MT, Voss TS, Marty AJ, Duffy MF, Good RT, Thompson JK, Freitas-Junior LH, Scherf A, Crabb BS, Cowman AF 2005. Heterochromatin silencing and locus repositioning linked to regulation of virulence genes in Plasmodium falciparum. Cell 121: 13-24.

Engler RJM 2001. Mosquito bite pathogenesis in necrotic skin reactors. Curr Opin Allergy Clin Immunol 1: 349-352.

Engwerda CR, Good MF 2005. Interactions between malaria parasites and the host immune system. Curr Opin Immunol 17: 381-387.

Escalante AA, Cornejo OE, Freeland DE, Poe AC, Durrego E, Collins WE, Lal AA 2005. A monkey's tale: The origin of Plasmodium vivax as a human malaria parasite. Proc Natl Acad Sci USA102: 1980-1985.

Ewald PE 1983. Host-parasite relations, vectors, and the evolution of disease severity. Ann Rev Ecol Syst 14: 465-485.

Feyereisen R 2006. Evolution of insect P450. Biochem Soc Trans 34: 1252-1255.

Flick K, Chen Q 2004. var genes, PfEMP1 and the human host. Mol Bioch Paras 134: 3-9.

Flint J, Harding RM, Boyce AJ, Clegg JB 1993. The population genetics of the haemoglobinopathies. Ballieres Clin Haematol 6: 215-262.

Flint J, Harding RM, Boyce AJ, Clegg JB 1998. The population genetics of the haemoglobinopathies. Baillieres Clin Haematol 11: 1-51.

Flint J, Hill AVS, Bowden DK, Oppenheimer SJ, Sill PR, Serjeantson SJ, Bana-Koiri J, Bhatia K, Alpers MP, Boyce AJ, Weatherall DJ, Clegg JB 1986. High frequencies of $\alpha$ thalassaemia are the result of natural selection by malaria. Nature 321: 744-750.

Fraser HB 2006. Coevolution, modularity and human disease. Curr Opin Gen Develop 16: 637-644.

Freitas-Junior LH, Hernandez-Rivas R, Ralph AS, Montiel-Condado D, Ruvalcaba-Salazar OK, Rojas-Meza AP, Mâncio-Silva L, Leal-Silvestre RJ, Gontijo AM, Shorte S, Scherf A 2005. Telomeric heterochromatin propagation and histone acetylation control mutually exclusive expression of antigenic variation genes in malaria parasites. Cell 121: 25-36.

Gardiner DL, Dixon MWA, Spielmann T, Skinner-Adams TS, Hawthorne PL, Ortega MR, Kemp DJ, Trenholme KR 2005. Implication of a Plasmodium falciparum gene in the switch between asexual reproduction and gametocytogenesis. Mol Biochem Parasitol 140: 153-160.

Gardner MJ, Hall N, Fung E, White O, Berriman M, Hyman RW, Carlton JN, Pain A, Nelson KE, Bowman S, Paulsen IT, James K, Eisen JA, Rutherford K, Salzberg SL, Craig A, Kyes S, Chan M-S, Nene V, Shallom SJ, Suh B, Peterson J, Angiuoli S, Pertea M, Allen J, Selengut J, Haft D, Mather MW, Vaidya AB, Martin DMA, Fairlamb AH, Fraunholz MJ, Roos DS, Ralph SA, McFadden JI, Cummings LM, Subramanian GM, Mungall C, Venter JC, Carucci DJ, Hoffman SL, Newbold C, Davi RW, Fraser CM, Barrell B 2002. Genome sequence of the human malaria parasite Plasmodium falciparum. Nature 419: 498-511
Ghiselin MT 1966. On semantic pitfalls of biological adaptation. Philos Sci 33: 147-153.

Gill SR, Pop M, DeBoy RT, Eckburg PB, Turnbaugh PJ, Samuel BS, Gordon JI, Relman DA, Fraser-Liggett CM, Nelson KE 2006. Metagenomic analysis of the human distal gut microbiome. Science 312: 1355-1359.

Gouagna LC, Mulder B, Noubissi E, Tchuinkam T, Verhave JP, Boudin C 1998. The early sporogonic cycle of Plasmodium falciparum in laboratory-infected Anopheles gambiae: an estimation of parasite efficacy. Trop Med Int Health 3: 21-28.

Greenwood B 1987. Asymptomatic malaria infections - Do they matter? Parasitol Today 3: 206-214.

Greenwood B 2006. Intermittent preventive treatment - A new approach to the prevention of malaria in children in areas with seasonal malaria transmission. Trop Med Int Health 11: 983-991.

Greenwood B, Mutabingwa T 2002. Malaria in 2002. Nature 415: 670-672.

Greenwood BM, David PH, Otoo-Forbes LN, Allen SJ, Alonso PL, Armstrong-Schellenbertg JR, Byass P, Hurwitz M, Menon A, Snow RW 1995. Mortality and morbidity from malaria after stopping malaria chemoprophylaxis. Trans $R$ Soc Trop Med Hyg 89: 629-633.

Gregson A, Plowe CV 2005. Mechanisms of resistance of malaria parasites to antifolates. Pharmacol Rev 57: 117-145.

Haldane JBS 1948. The rate of mutation of human genes. Hereditas (Suppl.) 5: 267-273.

Hastings IM, Paget-McNicol S, Saul A 2004. Can mutation and selection explain virulence in human $P$. falciparum infections? Malaria J 3: 2.

Hedges DJ, Batzer MA 2005. From the margins of the genome: mobile elements shape primate evolution. BioEssays 27: 785-794.

Hemingway J, Field L, Vontas J 2002. An overview of insecticide resistance. Science 298: 96-97.

Hemingway J, Hawkes NJ, McCarroll L, Ranson H 2004. The molecular basis of insecticide resistance in mosquitoes. Insect Biochem Mol Biol 34: 653-665.

Herrera S, Corradin G, Arévalo-Herrera M 2007. An update on the search for a Plasmodium vivax vaccine. Trends Parasitol (in press)

Hillyer JF, Schmidt SL, Christensen BM 2003. Rapid phagocytosis and melanization of bacteria and Plasmodium sporozoites by hemocytes of the mosquito Aedes aegypti. J Parasitol 89: 62-69.

Holt RA, Subramanian GM, Halpern A, Sutton GG, Charlab R, Nusskern DR, Wincker P. Clark AG, Ribeiro JMC, Wides R, Salzberg SL 2002. The genome sequence of the malaria mosquito Anopheles gambiae. Science 298:120-141.

Horsmanheimo L, Harvima IT, Harvima RJ, BrummerKorvenkontio H, François G, Reunala T 1996. Histamine and leukotriene $\mathrm{C} 4$ release in cutaneous mosquito-bite reactions. J Allergy Clin Immunol 98: 408-411.

Horwitz P, Wilcox BA 2005. Parasites, ecosystems and sustainability: an ecological and complex systems perspective. Int J Paras 35: 725-732. 
Hughes AL, Friedman R 2005. Poxvirus genome evolution by gene gain and loss. Mol Phylogen Evol 35: 186-195.

Hurd H 2007. Nature or nurture in mosquito resistance to malaria? Trends Parasitol (in press).

Jeffares DC, Pain A, Berry A. Cox AV, Stalker J, Ingle CE, Thomas A, Quail MA, Siebenthall K, Uhlemann A-C, Kyes S, Krishna S, Newbold C, Dermitzakis ET, Berriman M 2007. Genome variation and evolution of the malaria parasite Plasmodium falciparum. Nat Gen 39: 120-125.

Katzourakis A, Rambaut A, Pybus OG 2005. The evolutionary dynamics of endogenous retroviruses. Trends Microbiol 13: 463-468.

Kidgell C, Volkman SK, Daily J, Borevitz JO, Plouffe D, Zhou Y, Johnson JR, Le Roch KG, Sarr O, Ndir O, Mboup S, Batalov S, Wirth DF, Winzeler EA 2006. A systematic map of genetic variation in Plasmodium falciparum. PLoS Pathog 2: e57.

Kidwell MG, Lisch DR 2000. Transposable elements and host genome evolution. Trends Ecol Evol 15: 95-99.

Kim W, Koo H, Richman AM, Seeley D, Vizioli J, Klocko AD, O'Brochta DA 2004. Ectopic expression of a cecropin transgene in the human malaria vector mosquito Anopheles gambiae (Diptera: Culicidae): effects on susceptibility to Plasmodium. J Med Entomol 41: 447-455.

Koenraadt CJM, Paaijmans KP, Githeko AK, Knols BGHJ, Takken W 2003. Egg hatching, larval movement and larval survival of the malaria vector Anopheles gambiae in desiccating habitats. Malaria J 2: 20.

Kooij TWA, Janse CJ, Waters AP 2006. Plasmodium post-genomics: better the bug you know? Nat Rev Microbiol 4: 344-357.

Kumar S, Christophides GK, Cantera R, Charles B, Han YS, Meister S, Dimopoulos G, Kafatos FC, Barillas-Mury C 2003. The role of reactive oxygen species on Plasmodium melanotic encapsulation in Anopheles gambiae. Proc Natl Acad Sci USA 100:14139-14144.

Kwiatkowski DP 2005. How malaria has affected the human genome and what human genetics can teach us about malaria. Am J Hum Genet 77: 171-190.

Kyes S, Horrocks P, Newbold C 2001. Antigenic variation at the infected red cell surface in malaria. Annu Rev Microbiol 55: 673-707.

Ladeia-Andrade S 2005. Aspectos Epidemiológicos da Malária no Parque Nacional do Jaú, Amazonas, Brasil, PhD Thesis, Instituto Oswaldo Cruz-Fiocruz, Rio de Janeiro, 287 pp.

Lambrechts L, Halbert J, Durand P, Gouagna LG, Koella JC 2005. Host genotype by parasite genotype interactions underlying the resistance of anopheline mosquitoes to Plasmodium falciparum. Malaria J 4: 3.

Land KM 2003. The mosquito genome: perspectives and possibilities. Trends Parasitol 19: 103-105.

Lander ES, the International Human Genome Sequencing Consortium 2001. Initial sequencing and analysis of the human genome. Nature 409: 860-921.

Legorreta-Herrera M, Ventura-Ayala ML, Licona-Chávez RN, Soto-Cruz I, Hernández-Clemente FF 2004. Early treatment during a primary malaria infection modifies the development of cross immunity. Parasit Immunol 26: 7-17.

Lenzi HL, Vannier-Santos MA 2005. Interface parasito-hos- pedeiro. Coabitologia - Uma visão diferente do fenômeno parasitismo In JR Coura, Dinâmica das Doenças Infecciosas e Parasitárias, Guanabara-Koogan, Rio de Janeiro, p. 19-44.

Ley RE, Peterson DA, Gordon JI 2006. Ecological and evolutionary forces shaping microbial diversity in the human intestine. Cell 124: 837-848.

Llinás M, Bozdech Z, Wong ED, Adai AT, DeRisi JL 2006. Comparative whole of genome transcriptome analysis of three Plasmodium falciparum strains. Nucleic Acids Res 34: 1166-1173.

Luckhart S, Li K, Dunton R, Lewis EE, Crampton AL, Ryan JR, Rosenberg R 2003. Anopheles gambiae immune gene variants associated with natural Plasmodium infection. Mol Biochem Parasitol 128: 83-86.

Mac Gregor IA 1964. Studies in the acquisition of immunity to Plasmodium falciparum infections in Africa. Trans $R$ Soc Trop Med Hyg 58: 80-92.

Mackintosh CL, Beeson JG, Marsh K 2004. Clinical features and pathogenesis of severe malaria. Trends Parasitol 20: 597-603.

Maitland K, Marsh K 2004. Pathophysiology of severe malaria in children. Acta Trop 90: 131-140.

Marcano TJ, Morgado A, Tosta CE, Coura JR 2004. Cross-sectional study defines differences in malaria morbidity in two Yanomami communities on Amazonian boundary between Brazil and Venezuela. Mem Inst Osw Cruz 99: 369-376.

Marinotti O, Calvo E, Nguyen QK, Dissanayake S, Ribeiro JMC, James AA 2006. Genome-wide analysis of gene expression in adult Anopheles gambiae. Insect Mol Biol 15: 1-12.

Martinez-Torres D, Chandre F, Williamson MS, Darriet F, Berge JB, Devonshire AL, Guillet P, Pasteur N, Pauron D 1998. Molecular characterization of pyrethroid knockdown resistance $(k d r)$ in the major malaria vector Anopheles gambiae s.s. Insect Mol Biol 7: 179-184.

Mathenge EM, Gimnig JE, Kolczak M, Ombok M, Irungu W, Hawley WA 2001. Effect of permethrin-impregnated nets on exiting behaviour, blood feeding success, and time of feeding of malaria mosquitoes (Diptera: Culicidae) in Western Kenya. J Med Entomol 3: 531-536.

Matuschewski K 2006a. Getting infectious: formation and maturation of Plasmodium sporozoites in the Anopheles vector. Cell Microbiol 8: 1547-1556.

Matuschewski K 2006b. Vaccine development against malaria. Curr Opin Immunol 18: 449-457.

Mbogo CNM, Baya NM, Ofulla AVO, Githure JI, Snow RW 1996. The impact of permethrin-impregnated bednets on malaria vectors of the Kenyan coast. Med Vet Entomol 10: 251-259.

McCormack DR, Salata KF, Hershey JN, Carpenter GB, Engler RJ 1995. Mosquito bite anaphylaxis: immunotherapy with whole body extracts. Ann Allergy Asthma Immunol 74: 39-44.

McFadden G, Murphy PM 2000. Host-related immunomodulators encoded by poxviruses and herpesviruses. Curr Opin Microbiol 3: 371-378.

McGreevy PB, Dietze R, Prata A, Hembree SC 1989. Effects of immigration on the prevalence of malaria in rural areas of the Amazon Basin of Brazil. Mem Inst Osw Cruz 84: 485-491.

Menge DM, Zhong D, Guda T, Gouagna L, Githure J, Beier J, 
Yan G 2006. Quantitative trait loci controlling refractoriness to Plasmodium falciparum in natural Anopheles gambiae mosquitoes from a malaria-endemic region in Western Kenya. Genetics 173: 235-247.

Michel IK, Kafatos FC 2005. Mosquito immunity against Plasmodium. Insect Biochem Mol Biol 35: 677-689.

Michel K, Suwanchaichinda C, Morlais I, Lambrechts L, Cohuet A, Awono-Ambene PA, Simard F, Fontenille D, Kanost MR, Kafatos FC 2006. Increased melanizing activity in Anopheles gambiae does not affect development of Plasmodium falciparum. Proc Natl Acad Sci USA 103: 16858-16863.

Miller LH, Good MF, Millon G 1994. Malaria pathogenesis. Science 264: 1878-1883.

Minakawa N, Githure JI, Beier JC, Yan G 2001. Anopheline mosquito survival strategies during the dry period in Western Kenya. J Med Entomol 38: 388-392.

Min-Oo G, Gros P 2005. Erythrocyte variants and the nature of their malaria protective effect. Cell Microbiol 7: 753-763.

Modiano D, Luoni G, Sirima BS, Simpore J, Verra F, Konate A, Rastrelli E, Olivieri A, Calissano C, Paganotti GM, D'Urbano L, Sanou I, Sawadogo A, Modiano G, Coluzzi M 2001. Haemoglobin C protects against clinical Plasmodium falciparum malaria. Nature 414: 305-308.

Morlais I, Poncon N, Simard F, Cohuet A, Fontenille D 2004. Intraspecific nucleotide variation in Anopheles gambiae: New insights into the biology of malaria vectors. Am J Trop Med Hyg 71: 795-802.

Mukhtar M, Herrel N, Amerasinghe FP, Ensink J, van der Hoek W, Konradsen F 2003. Role of wastewater irrigation in mosquito breeding in south Punjab, Pakistan. Southeast Asian J Trop Med Public Health 34: 72-80.

Müller P, Donnelly MJ, Ranson H 2007. Transcription profiling of a recently colonised pyrethroid resistant Anopheles gambiae strain from Ghana. BMC Genomics 8: 36.

Muniz-Junqueira MI, Tosta CE 2007. The pathological bases of immunomodulatory therapy in malaria. Antibiotiques (in press).

Nair S, Nash D, Sudimack D, Jaidee A, Barends M, Uhlemann A-C, Krishna S, Nosten F, Anderson TJC 2007. Recurrent gene amplification and soft selective sweeps during evolution of multidrug resistance in malaria parasites. Mol Biol Evol 24: 562-573.

Ndungu FM, Urban BC, Marsh K, Langhorne J 2005. Regulation of immune response by Plasmodium-infected red blood cells. Paras Immunol 27: 373-384.

Norris DE, Shurtleff AC, Toure YT, Lanzaro GC 2001. Microsatellite DNA polymorphism and heterozygosity among field and laboratory populations of Anopheles gambiae s.s. (Diptera: Culicidae). J Med Entomol 38: 336-340.

Oharshi J, Naka I, Patarapotikul J, Hananantachai H, Brittenham G, Looareesuwan S, Clark AG, Tokunaga K 2004. Extended linkage disequilibrium surrounding the hemoglobin $\mathrm{E}$ variant due to malarial selection. Am J Hum Genet 74: 1198-1208.

Omer SM, Cloudsley-Thompson JL 1970. Survival of female Anopheles gambiae Giles through a 9-month dry season in Sudan. Bull WHO 42: 319-330.

Otoo LN, Riley EM, Menon A, Byass P, Greenwood BM 1989. Cellular immune responses to Plasmodium falciparum antigens in children receiving long term anti-malarial chemopro- phylaxis. Trans $R$ Soc Trop Med Hyg 83: 778-782.

Owhashi M, Harada M, Suguri S, Ohmae H, Ishii A 2001. The role of saliva of Anopheles stephensi in inflammatory response: identification of a high molecular weight neutrophil chemotactic factor. Parasitol Res 87: 376-382.

Owusu-Agyei S, Koram KA, Baird JK, Utz GC, Binka FN, Nkrumah FK, Fryauff DJ, Hoffman SL 2001. Incidence of symptomatic and asymptomatic Plasmodium falciparum infection following curative therapy in adult residents of Northern Ghana. Am J Trop Med Hyg 65: 197-203.

Pates H, Curtis C 2005. Mosquito behavior and vector control. Annu Rev Entomol 50: 53-70.

Peng Z, Beckett AN, Engler RJ, Hoffman DR, Ott NL, Simons FE 2004a. Immune responses to mosquito saliva in 14 individuals with acute systemic allergic reactions to mosquito bites. J Allergy Clin Immunol 114: 1189-1194.

Peng Z, Ho MK, Li C, Simons FE 2004b. Evidence for natural desensitization to mosquito salivary antigens: mosquito saliva specific IgE and IgG levels in children. Ann Allerg Asthma Immunol 93: 553-556.

Phillips RS 2001. Current status of malaria and potential for control. Clin Microbiol Rev 14: 208-226.

Pombo DJ, Lawrence G, Hirunpetcharat C, Rzepczyk C, Bryden M, Cloonan N, Anderson K, Mahakunkijcharoen Y, Martin LB, Wilson D, Elliott S, Elliott S, Eisen DP, Weinberg JB, Saul A, Good MF 2002. Immunity to malaria after administration of ultra-low doses of red cells infected with Plasmodium falciparum. Lancet 360: 610-617.

Póvoa MM, Conn JE, Schlichting CD, Amaral JCOF, Segura MNO, Silva ANM, Santos CCB, Lacerda RNL, Souza RTL, Galiza D, Santa Rosa EP, Wirtz RA 2003. Malaria vectors, epidemiology, and the re-emergence of Anopheles darlingi in Belém, Pará, Brazil. J Med Entomol 40: 379-386.

Price RN, Uhlemann A-C, van Vugt M, Brockman AI, Hutagalung R, Nair S, Nash D, Singhasivanon P, Anderson TJC, Krishna S, White NJ, Nosten F 2006. Molecular and pharmacological determinants of the therapeutic response to artemetherlumefantrine in multi-drug resistant falciparum malaria. Clin Infect Dis. 42: 1570-1577.

Ranson H, Claudianos C, Ortelli F, Abgrall C, Hemingway J, Sharakhova MV, Unger MF, Collins FH, Feyereisen R 2002. Evolution of supergene families associated with insecticide resistance. Science 298: 179-181.

Ribeiro JM 1995. Blood-feeding arthropods: live syringes or invertebrate pharmacologists? Infect Agents Dis 4: 143-152

Riehle MM, Markianos K, Niaré O, Xu J, Li J, Touré AM, Podiougou B, Diawara FS, Diallo M, Coulibaly B, Ouatara A, Kruglyak L, Traoré SF, Vernick KD 2006. Natural malaria infection in Anopheles gambiae is regulated by a single genomic control region. Science 312: 577-579.

Rolff J 2007. Why did the acquired immune system of vertebrates evolve? Develop Comp Immunol 31: 476-482.

Rosen JB, Breman JG 2004. Malaria intermittent preventive treatment in infants, chemoprophylaxis, and childhood vaccinations. Lancet 363: 1386-1388.

Sabeti PC, Reich DE, Higgins JM, Levine HZP, Richter DJ, Schaffner SF, Gabriel SB, Platko JV, Patterson NK, McDonald GJ, Ackerman HC, Campbell SJ, Altshuler D, Cooperk R, Kwiatkowski D, Ward R, Lander ES 2002. De- 
tecting recent positive selection in the human genome from haplotype structure. Nature 419: 832-837.

Sattler MA, Mtasiwa D, Kiama M, Premji Z, Tanner M, Killeen GF, Lengeler C 2005. Habitat characterization and spatial distribution of Anopheles sp. mosquito larvae in Dar es Salaam (Tanzania) during an extended dry period. Malaria J 4: 4.

Schellenberg D, Cisse B, Menendez C 2006. The IPTi Consortium: research for policy and action. Trends Parasitol 22: 296-300.

Schellenberg D, Menendez C, Aponte JJ, Kahigwa E, Tanner M, Mshinda H, Alonso P 2005. Intermittent preventive antimalarial treatment for Tanzanian infants: follow up to age 2 years of a randomised, placebo-controlled trial. Lancet 365: 1481-1483.

Schmid-Hempel P 2003. Variation in immune defence as a question of evolutionary ecology. Proc Biol Sci 270: 357-366.

Schmid-Hempel P, Ebert D 2003. On the evolutionary ecology of specific immune defence. Trends Ecol Evol 18: 27-32.

Seet BT, Johnston JB, Brunetti CR, Barrett JW, Everett H, Cameron C, Sypula J, Nazarian SH, Lucas A, McFadden G 2003. Poxviruses and immune evasion. Ann Rev Immunol 21:377-423.

Shedlock AM, Takahashi K, Okada N 2004. SINEs of speciation: tracking lineages with retroposons. Trends Ecol Evol 19: 545-553.

Shibasaka M, Sumzaki R, Takita H 1986. Hypersensitivity reactions to mosquito bites in congenital agammaglobulinemia. Ann Allergy 56:81-84.

Shiff C 2002. Integrated approach to malaria control. Clin Microbiol Rev 15: 278-293.

Sidhu AB, Verdier-Pinard D, Fidock DA 2002. Chloroquine resistance in Plasmodium falciparum malaria parasites conferred by pfcrt mutations. Science 298: 210-213.

Sidhu AB, Uhlemann A-C, Valderramos SG, Valderramos JC, Krishna S, Fifock DA 2006. Decreasing $p f m d r 1$ copy number in Plasmodium falciparum malaria heightens susceptibility to mefloquine, lumefantrine, halofantrine, quinine, and artemisinin. J Infect Dis 194: 528-535.

Simon FE, Peng Z. Skeeter syndrome 1999. J Allergy Clin Immunol 104: 705-707.

Sinden RE, Alavi Y, Raine JD 2004. Mosquito-malaria interactions: A reappraisal of the concepts of susceptibility and refractoriness. Insect Biochem Mol Biol 34: 625-629.

Snounou G, Rénia L 2007. The vaccine is dead - Long live the vaccine. Trends Parasitol (in press)

Srivastava IK, Morrisey JM, Darrouzet E, Daldal F, Vaidya AB 1999. Resistance mutations reveal the atovaquone-binding domain of cytochrome b in malaria parasites. Mol Microbiol 33: 704-711.

Stump AD, Atieli FK, Vulule JM, Besansky NJ 2004. Dynamics of the pyrethroid knockdown resistance allele in western Kenyan populations of Anopheles gambiae in response to insecticide treated bed net trials. Am J Trop Med Hyg 70: 591-596.

Su X-Z, Mu J, Joy DA 2003. The "Malaria's Eve" hypothesis and the debate concerning the origin of the human malaria parasite Plasmodium falciparum. Microb Infect 5: 891-896.

Summers K, McKeon S, Sellars J, Keusenkothen M, Morris J, Gloeckner D, Pressley C, Price B, Snow H 2003. Parasitic exploitation as an engine of diversity. Biol Rev 78: 639-675.
Tadei WP, Thatcher BD 2000. Malaria vectors in the Brazilian Amazon: Anopheles of the subgenus Nyssorhynchus. Rev Inst Med Trop São Paulo 42: 87-94.

Tadei WP, Thatcher BD, Santos JMH, Scarpassa VM, Rodrigues IB, Rafael MS 1998. Ecologic observations on anopheline vectors of malaria in the Brazilian Amazon. Am J Trop Med Hyg 59: 325-335.

Targett GA 1988. Plasmodium falciparum: natural and experimental transmission-blocking immunity. Immunol Lett 19: 235-240.

Taylor LH 1999. Infection rates in, and the number of Plasmodium falciparum genotypes carried by Anopheles mosquitoes in Tanzania. Ann Trop Med Parasitol 93: 659-662.

Titus RG, Bishop JV, Mejía JS 2006. The immunomodulatory factors of arthropod saliva and the potential for these factors to serve as vaccine targets to prevent pathogen transmission. Paras Immunol 28: 131-141.

Tosta CE 2001. Coevolutionary networks: a novel approach to understanding the relationships of humans with the infectious agents. Mem Inst Osw Cruz 96: 415-425.

Tosta CE, Muniz-Junqueira MI, Sala Neto, F 2005. Imunologia das relações do plasmódio com o hospedeiro humano. In JR Coura, Dinâmica das Doenças Infecciosas e Parasitárias, Guanabara-Koogan, Rio de Janeiro, p. 865-874.

Trape JF, Rogier C, Konate L, Diagne N, Bouganali H, Canque B, Legros F, Badji A, Ndiaye G, Ndiaye P, Brahimi K, Faaye O, Druilhe P, Pereira da Silva L 1994. The Dielmo Project: a longitudinal study of natural malaria infection and the mechanisms of protective immunity in a community living in a holoendemic area of Senegal. Am J Trop Med Hyg 51: 123-137.

Trung HD, Bortel WV, Sochantha T, Keokenchanh K, Briët OJT, Coosemans M 2005. Behavioural heterogeneity of Anopheles species in ecologically different localities in Southeast Asia: a challenge for vector control. Trop Med Int Health 10: 251-262.

Tu Z, Coates C 2004. Mosquito transposable elements. Insect Bioch Mol Biol 34: 631-644.

Ustyugova SV, Lebedev YB, Sverdlov ED 2006. Long L1 insertions in human gene introns specifically reduce the content of corresponding primary transcripts. Genetica 128: 261-272.

Vaughan JA 2007. Population dynamics of Plasmodium sporogony. Trends Parasitol 23: 63-70.

Vittor AY, Gilman RH, Tielsch J, Glass G, Shields T, Lozano WS, Pinedo-Cancino V, Patz JA 2006 The effect of deforestation on the human-biting rate Anopheles darlingi, the primary vector of falciparum malaria the Peruvian Amazon. Am $J$ Trop Med Hyg 74: 3-11.

Vlachou D, Kafatos FC 2005. The complex interplay between mosquito positive and negative regulators of Plasmodium development. Curr Opin Microbiol 8: 415-421.

Vulule JM, Beach RF, Ayieli FK, Roberts JM, Mount DL, Mwangi RW 1994. Reduced susceptibility of Anopheles gambiae to permethrin associated with the use of permethrin-impregnated bednets and curtains in Kenya. Med Vet Entomol 8: 71-75.

Wasserman HA, Singh S, Champagne DE 2004. Saliva of the yellow fever mosquito, Aedes aegypti, modulates murine lymphocyte function. Parasite Immunol 26: 295-306.

Weatherall DJ, Clegg JB 2001. Inherited haemoglobin disorders: an increasing global health problem. Bull WHO 79: 704-712. 
Weatherall DJ, Clegg JB 2002. Genetic variability in response to infection: malaria and after. Genes Immun 3: 331-337.

Weatherall DJ, Clegg J, Kwiatkowski D 1997. The role of genomics in studying genetic susceptibility to infectious disease. Genome Res 7: 967-973.

Wellems TE 1990. Chloroquine resistance not linked to $m d r$-like genes in a Plasmodium falciparum cross. Nature 345: 253-255.

West-Eberhard MJ 2005. Developmental plasticity and the origin of species differences. Proc Natl Acad Sci USA 120 (Suppl. 1): 6543-6549.

White NJ 2006. Modelling malaria control. PLOS Med 3: e111.

Whitelaw NC, Whitelaw E 2006. How lifetimes shape epigenotype within and across generations. Human Mol Gen 15: 131-137.

WHO 2005a. World Malaria Report 2005, Geneva.
WHO 2005b. Susceptibilty of Plasmodium falciparum to antimalarial drugs. Report on global monitoring 1994-2004, Geneva.

WHO / MVI / Wellcome Trust / Bill\&Melinda Gates Foundation 2006. Global strategy aims for effective malaria vaccine by 2025. Joint note for the press, 4 December 2006.

Williams TN 2006. Red blood cell defects and malaria. Mol Biochem Paras 149: 121-127.

Woolhouse MEJ, Webster JP, Domingo E, Charlesworth B, Levin BR 2002. Biological and biomedical implications of the co-evolution of pathogens and their hosts. Nat Gen 32: 569-577.

Wykes M, Keighley C, Pinzon-Charry A, Good MF 2007. Dendritic cell biology during malaria. Cell Microbiol 9: 300-305.

Yamey G 2004. Roll back malaria: a failing global health campaign. Brit Med J 328: 1086-1087. 